\title{
ZWISCHEN PANEGYRIK UND TATSACHENBERICHT
}

Zu Struktur und Zielsetzung von Medienereignissen zur Zeit Maria Theresias*

\author{
Werner Telesko, Sandra Hertel und Stefanie Linsboth
}

Die Regierungszeit Maria Theresias (1717-1780, reg. 1740-1780) ist überaus reich an historischen Ereignissen: Kriege und Friedensschlüsse, Geburten und Todesfälle, politische Erfolge und persönliche Schicksalsschläge strukturierten die Periode der Herrschaft der Habsburgerin. ${ }^{1}$ Die vorliegenden Ausführungen untersuchen drei verschiedene, historisch essentielle Geschehen vorwiegend, aber nicht ausschließlich in ihrer Dimension und Funktion als Medienereignisse: die Geburt des Thronfolgers Joseph (1741), die Schlacht von Kolín (1757) und Maria Theresias Genesung von den Blattern (1767). Anhand dieser Ereignisse und ihrer dichten medialen Präsenz, die durchgehend die eigentlichen Handlungskerne der Geschehen überhöht, lassen sich wesentliche Einsichten in das komplexe Verhältnis zwischen den Medienproduzenten einerseits und den verschiedenen Öffentlichkeiten der mariatheresianischen Ära andererseits gewinnen. Untersucht werden im Folgenden die Öffentlichkeitsstrategien der medienproduzierenden Akteure sowie die Informationsintentionen anhand der verwendeten Medien, darunter vor allem Zeitungen, Druckschriften, Flugblätter, Medaillen, Stiche, Gemälde, ephemere Architektur und Predigten. „Öffentlichkeit“ ist im 18. Jahrhundert vorwiegend im Sinne einer allgemein zugänglichen Kategorie und nicht als „staatlich“ zu verstehen. ${ }^{2}$ Gemeint sind damit vor allem jene verschiedenen Räume, in denen Nachrichten ausgetauscht und die Mechanismen von Kommunikation praktiziert wurden. Öffentlichkeit wird dabei durch die benutzten Medien erst hergestellt, wobei man angesichts unterschiedlicher Schichten und Adressatenkreise im besprochenen Zeitraum bewusst im Plural, also von unterschiedlichen Öffentlichkeiten sprechen muss. ${ }^{3} \mathrm{Zu}$ diesen zählte in der Frühen Neuzeit beispielsweise die höfische

\footnotetext{
* Dieser Beitrag erschien erstmals in der Zeitschrift für Historische Forschung: Werner Telesko / Sandra Hertel / Stefanie Linsboth, Zwischen Panegyrik und Tatsachenbericht - zu Struktur und Zielsetzung von „Medienereignissen“ zur Zeit Maria Theresias, in: Zeitschrift für Historische Forschung 44 (2017), H. 3, 441486.

Die Anteile der Autorschaft an diesem Beitrag gliedern sich wie folgt: Gemeinsam wurden Einleitung und Fazit verfasst; Sandra Hertel zeichnet für den Abschnitt zur Geburt Josephs (II.) verantwortlich, Werner Telesko für jenen zur Schlacht von Kolín und Stefanie Linsboth für das Kapitel zur Genesung Maria Theresias.

${ }^{1}$ Der vorliegende Beitrag entstand im Rahmen des Projekts 27512 „Herrscherrepräsentation und Geschichtskultur unter Maria Theresia (1740-1780)“ des Österreichischen Wissenschaftsfonds, durchgeführt unter der Leitung von Werner Telesko an der Österreichischen Akademie der Wissenschaften, Institut für kunstund musikhistorische Forschungen, Abteilung Kunstgeschichte.

${ }^{2}$ Opgenoorth, Kommunikationsgeschichte, 44.

${ }^{3}$ Küster, Vier Monarchien, 20 f.
} 
Öffentlichkeit, die das Nachrichtennetzwerk der europäischen Höfe und deren gegenseitige Beobachtung umfasste. ${ }^{4}$ Zudem existierten weitere Teilöffentlichkeiten, die durch unterschiedliche soziale Schichten und Interessengruppen gebildet wurden. ${ }^{5}$ Auch die mündliche Weitergabe von Nachrichten hatte im 18. Jahrhundert noch eine große Bedeutung, weshalb auch die Partizipation weniger gebildeter Schichten an der Mediengesellschaft nicht zu unterschätzen ist. ${ }^{6}$ Harriet Rudolph hat in ihrer grundlegenden Untersuchung zu Formen und Funktionen von Kaisereinzügen in der Frühen Neuzeit deutlich gemacht, dass zwischen den Kategorien der „Präsenzöffentlichkeit“ und der „Medienöffentlichkeit“ zu unterscheiden ist. ${ }^{7}$ Wiewohl beide Öffentlichkeiten in ihrer faktischen Ausprägung heute nicht mehr präzise erschlossen werden können, ist der Umstand von zentraler Bedeutung, dass die Medienöffentlichkeit weit über die Öffentlichkeit beim faktischen Ereignis vor Ort hinausreichte. Die in diesen Ausführungen untersuchten Text- und Bildzeugnisse sollen die entsprechende Basis bilden, um die „Medienöffentlichkeit“ im Spannungsfeld von Produzenten und Rezipienten präziser definieren zu können.

Für eine strukturelle Analyse der verschiedenen Ereignisse und der Dynamik ihrer medialen Vermittlung ist es zudem sinnvoll, zwischen dem spontanen Nachrichten- oder Kommunikationsereignis und dem angekündigten Medienereignis, wie etwa die von Rudolph analysierten Herrscherinszenierungen, ${ }^{8}$ zu unterscheiden. ${ }^{9}$ In dieser Hinsicht sind angesichts der Unvorhersehbarkeit von Entwicklungen, wie die Genesung von einer Krankheit oder militärische Erfolge, Strukturen und Prozesse der Medialisierung von Nachrichten vor allem im Hinblick auf Reaktion und Flexibilität zu betrachten. Während beispielsweise eine Geburt ein zumindest teilweise vorhersehbares Ereignis darstellt, ist die politische Brisanz ihres Ergebnisses nicht planbar.

Herrscherrepräsentation kann grundsätzlich als kontinuierliche Informationspraxis angesehen werden, kumuliert aber in herrschaftsrelevanten Momenten, die zu bestimmten von Herrscher und Untertanen gemeinsam wahrgenommenen Ereignissen stilisiert und medial verstärkt werden. Zweck dieser Medienereignisse, die verdichtete Kommunikationssituationen anzeigen bzw. auslösen, ist letztlich die Positionierung von Botschaften vor einer größtmöglichen Öffentlichkeit, wobei die spezifischen Eigenheiten der beteiligten Medien und ihrer Adressatenkreise nicht unerheblich voneinander divergieren.

\footnotetext{
${ }^{4}$ Bauer, Mediengeschichte; ders., Nachrichtenmedien, 174.

${ }^{5}$ Körber, Flugschriften.

${ }^{6}$ Böning, Der ,gemeine Mann“ als Zeitungs- und Medienkonsument, $227 \mathrm{f}$.

${ }^{7}$ Rudolph, Das Reich als Ereignis, 422 (zusammenfassend).

${ }^{8}$ Rudolph, Das Reich als Ereignis, 422 (zusammenfassend).

${ }^{9}$ Drentwett, Medienberichterstattung, 102.
} 
Die hier anhand dreier unterschiedlicher Geschehen näher charakterisierten Bild- und Textmedien machen nicht nur die Ereignisse beobachtbar, die sie vermitteln, sondern sie geben im Rahmen der Prozesse der Medialisierung zugleich nähere Auskunft über die jeweilige Medienformation selbst, da die Medienproduzenten notwendigerweise auch über den richtigen Einsatz und die Treffsicherheit der angewendeten Darstellungstechniken im Verhältnis zur jeweils angesprochenen Öffentlichkeit zu reflektieren hatten.

In den medialen Präsentationen von Ereignissen fanden - stets unter den prägenden Leitmotiven von Anschaulichkeit und Vermittelbarkeit - „Konzentrations- und Selektionsprozesse“ statt, die das jeweilige vielgestaltige Geschehen überhaupt erst als einheitliches Ganzes wahrnehmbar und kommunizierbar werden ließen. ${ }^{10}$ Die Visualisierungen frühneuzeitlicher Schlachten zeigen etwa, dass sich Medienereignisse als „diskursiv und medial erzeugte, perspektivenabhängige, kulturell spezifische und historisch variable Konstrukte“11 bezeichnen lassen. Ein komplexer „Medienverbund“ aus Bildern, Zeitungen und Relationen, „der das Ereignis durch seine Repräsentation im Grunde erst produzierte“, hatte in diesem Sinn ein mehr oder minder „verbindliches Narrativ des Geschehenen zu etablieren“12 - mit dem durchgängig zu beobachtenden Ziel, Komplexität zugunsten der Fokussierung auf einige wenige einprägsame, aber anschaulich vermittelbare Handlungsfolgen zu reduzieren. Dieser als Narrativierung beschreibbare Prozess verläuft in der Weise, dass einzelne Handlungsmomente innerhalb eines Ereignisses in temporale und kausale Sequenzen überführt werden. Dabei vermochten Medienereignisse auch emotionale Ergriffenheit bei ihren Rezipienten zu generieren, da ihnen auf der Ebene der Informationsvermittlung eine historische Bedeutung und Außergewöhnlichkeit verliehen wurde. ${ }^{13}$ Es wird anhand der Disposition und Intention der überlieferten Zeugnisse detailliert zu analysieren sein, in welcher Weise die unterschiedlichen Medien unmittelbar daran beteiligt waren, aus einer komplexen Ereignisfolge ein Konstrukt herauszupräparieren, ob also - verkürzt formuliert - das jeweilige Ereignis eigentlich erst durch die Medien „gemacht“ wurde oder ob der Gesichtspunkt einer erst sekundären Visualisierung und Vermittlung des Geschehens durch die entsprechenden Medien im Fokus stand.

Die spezifischen Ausformungen von Medienereignissen richteten sich - auch auf der Basis der Relevanz des Inhalts des Geschehens - immer nach unterschiedlichen Gruppen von Empfängern, womit in den folgenden Ausführungen eine enge inhaltliche Verschränkung von

\footnotetext{
${ }^{10}$ Weißbrich / Carl, Präsenz, 93; Bösch / Schmidt (Hrsg.), Performanz (mit einem fokussierten methodischen Blick auf die Zusammenhänge zwischen Ereignis, Medien und Performanz).

${ }^{11}$ Nünning, Medienereignis, 188.

${ }^{12}$ Füssel, Das Undarstellbare, 330.

${ }^{13}$ Bösch, Europäische Medienereignisse, 7.
} 
Fragestellungen zum spezifischen Charakter von Medienereignissen einerseits und zu den adressierten Öffentlichkeiten andererseits als sinnvoll und zweckmäßig erscheint: Einige Publikationen im besprochenen Zeitraum orientierten sich an breiten Schichten der Bevölkerung, teilweise sogar an allen Einwohnern der Österreichischen Erblande bzw. des Heiligen Römischen Reiches. Für einen deutlich engeren Rezipientenkreis war hingegen etwa das „Wienerische Diarium“14 vorgesehen und für einen noch kleineren Radius von Empfängern gedruckte Predigten sowie Prunkmedaillen. ${ }^{15}$ Die wöchentlich erscheinenden Lokalzeitungen, wie das erwähnte von Johann Peter van Ghelen (1673-1754) mit Privileg des Wiener Hofes herausgegebene „Wienerische Diarium“, erfüllten mit ihrer Mischung aus europäischen Nachrichten und höfischer Berichterstattung die aktuellen Informationsbedürfnisse. ${ }^{16}$ Zeitungen waren grundsätzlich Medien von mittlerer Reichweite, da sie in Kaffeehäusern auslagen und aus ihnen vorgelesen wurde; so kamen auf ein Exemplar etwa zehn Leser. ${ }^{17}$ Das „Wienerische Diarium“ hatte aufgrund des höfischen Druckprivilegs eine Sonderstellung unter den Zeitungen der Österreichischen Erblande inne. Der Verleger erhielt exklusive Informationen von Seiten des Hofes, wurde zensuriert und war verpflichtet, allen erbländischen Verlegern kostenlos ein aktuelles Druckexemplar zuzusenden. ${ }^{18}$ Dadurch sicherte sich der Hof zum einen das Nachrichtenmonopol und garantierte zum anderen eine schnellstmögliche Distribution der Neuigkeiten in den Erblanden. Andere gedruckte Schriften wie Gedichte, Flugblätter, Oden und Predigten sind hingegen den unterschiedlichen Gattungen der Herrscherpanegyrik zuzuordnen: Die Autoren nahmen ein konkretes Ereignis zum Anlass, dem Haus Habsburg und Maria Theresia im Allgemeinen zu huldigen, ihre Tugenden und ihr ruhmvolles Schicksal hervorzuheben. Diese gedruckten Medien können der Kategorie der „multiplizierenden Imagepflege“19 zugerechnet werden. Die entsprechenden Autoren handelten nicht im konkreten Auftrag, wohl aber im Sinne des Hofes und huldigten dem Herrscher aufgrund persönlicher und - in einigen Fällen - wirtschaftlicher Interessen, wodurch sie an der Herrscherrepräsentation einen entsprechend großen Anteil hatten. Unter den Wiener Autoren und Verlegern verstärkte sich auf der Basis dieser kompetitiven Situation die Konkurrenz. ${ }^{20}$

\footnotetext{
${ }^{14}$ Vgl. Gestrich, Kriegsberichterstattung.

${ }^{15}$ Küster, Vier Monarchien, $124 \mathrm{f}$.

${ }^{16}$ Seitschek, Zeremonialprotokoll, 56-58.

${ }^{17}$ Wilke, Zeitung, 396; Gestrich, Absolutismus, 130.

${ }^{18}$ FHKA, Sammlungen und Selekte, Kontrakte und Reverse, C-649, fol. 1v-2r.

${ }^{19}$ Schumann, Die andere Sonne, 36-38, 359-365.

${ }^{20}$ Karstens, Sonnenfels, 299 f.; ders., Lehrer. Bereits für das 16. und 17. Jahrhundert spielt der Gesichtspunkt des unternehmerischen Profits der Akteure eine Rolle; vgl. Rudolph, Das Reich als Ereignis, 421.
} 
Schon diese hier nur skizzenhaft umrissenen Sachverhalte machen deutlich, wie vereinfachend und unhistorisch es wäre, von einer zentralisierend-monarchischen Repräsentation mit einseitigen Durchgriffsmöglichkeiten der Dynastie zu sprechen, die im Hof ihr personelles Zentrum besaß. Am Beispiel der drei eingangs erwähnten unterschiedlich strukturierter Ereignisse der Ära Maria Theresias soll transparent werden, wie eng anlassgebundene Strategien der Repräsentation „von oben“ und „,von unten“ miteinander verflochten waren. Die drei Ereignisse aus der Epoche der Habsburgerin werden daher durchgehend nach bestimmten Parametern befragt, von denen folgende Fragestellungen besondere Relevanz besitzen: Ist die Medialisierung des jeweiligen Ereignisses typisch für die habsburgische Repräsentation? Welche Medien wurden für die Veranschaulichung der Ereignisse herangezogen? Welche Akteure und Intentionen lassen sich angesichts der medialen Produktion namhaft machen? Neben der Analyse des spezifischen Charakters des jeweiligen Medienereignisses soll die Auswertung der Quellen die unterschiedlichen Botschaften und Inhalte im Kontext der mariatheresianischen Repräsentation herausarbeiten. In einem Schlussabschnitt wird ein Fazit gezogen, das auch dem Problem der Vergleichbarkeit der hier vorgestellten Ereignisse nachgeht.

\section{Der ersehnte Thronfolger: Die Geburt Erzherzog Josephs im Jahr 1741}

Die Geburt eines männlichen Prinzen war in allen europäischen Monarchien der Frühen Neuzeit ein wichtiger dynastischer Moment, der eine innen- wie außenpolitische Dimension besaß. Zugleich war dies ein familiäres Ereignis, das in enger Verbindung zur Religiosität des Herrschers stand. Um eine Geburt herum sollten religiöse Rituale und Praktiken wie Dankgebete und die Taufe die damals nicht oder nur schwer beherrschbaren medizinischen Risiken einhegen. ${ }^{21}$

Die mediale Resonanz auf die Geburt eines Thronfolgers war je nach Dynastie und Zeitpunkt der Geburt unterschiedlich. Eine europaweit wahrgenommene Nachricht war sie in jedem Fall. $^{22}$ Der Geburt Josephs am 13. März 1741 kam aus dynastisch-politischen Gründen eine Sonderrolle zu: Kaiser Karl VI. war 1740 ohne männlichen Erben gestorben, und seine älteste Tochter Maria Theresia hatte bis zum Regierungsantritt nur drei Töchter zur Welt gebracht. Die Überlebensfähigkeit der durch die Heirat (1736) mit Franz Stephan (1708-1765) neu

\footnotetext{
${ }^{21}$ Systematische und vergleichende Untersuchungen zu Geburten von Thronfolgern in der Frühen Neuzeit stehen noch aus. Zur Geburt Josephs als Medienereignis vgl. Küster, Vier Monarchien, 102-107; zu Geburten im Haus Habsburg vgl. Stöckelle, Geburten.

${ }^{22}$ Die Nachrichten von Geburten in europäischen Fürstenhäusern wurden u. a. im Wienerischen Diarium veröffentlicht: vgl. hier den Bericht über die Geburt Dauphin Louis Ferdinands von Frankreich im Wienerischen Diarium vom 21. September 1729.
} 
begründeten Dynastie Habsburg-Lothringen hing ebenso wie die Durchsetzung von Maria Theresias Erbansprüchen von der Geburt eines männlichen Stammhalters ab. Im Dezember 1740 begann mit dem Einmarsch König Friedrichs II. von Preußen (1712-1786) in Schlesien der Österreichische Erbfolgekrieg.

Die Geburt selbst fand im geschlossenen Raum weiblicher Intimität statt, lediglich die Kaiserinwitwe Elisabeth Christine (1691-1750) als Mutter der Gebärenden und die weiblichen Obersthofmeisterinnen waren anwesend - insgesamt acht Frauen. ${ }^{23}$ Das Zeremonialprotokoll vermerkte über die Geburt um zwei Uhr morgens erleichtert, dass die ausgehung des männlichen Stammes des durchl. Erzhauses Österreich Gott gnädig dardurch wiedersetztet worden. ${ }^{24}$ Da die Geburt am Wiener Hof ohne partizipierende Öffentlichkeit praktiziert wurde, kam der Veröffentlichung der Nachricht eine größere Bedeutung zu als bei anderen dynastischen Ereignissen. Die Verbreitung der Nachricht in der Stadt entwickelte sich zu einem eigenständigen Kommunikationsereignis: Unmittelbar nach der Entbindung wurde die Information, ein Thronfolger sei geboren worden, aus den Retiraden der Wiener Hofburg hinaus der bereits wartenden Bevölkerung zugerufen und trotz der nächtlichen Stunde in Form von Vivat-Rufen innerhalb der Stadt Wien verbreitet. ${ }^{25}$ Erst in einem zweiten Schritt wurden andere Städte und Länder durch die Zeitungen und persönliche Schreiben des Hofes informiert. Die Bevölkerung der Erblande erfuhr von der Geburt in den Gottesdiensten, die in der Frühen Neuzeit durch die Obrigkeit gezielt zur Verbreitung von Informationen genutzt wurden. ${ }^{26}$

Das Kommunikationsereignis entwickelte sich in der Folge durch vom Hof anbefohlene Feierlichkeiten und Rituale und deren mediale Vervielfältigung und Deutung zu einem Medienereignis. Zu den spezifisch habsburgischen Ritualen nach der Geburt eines Erzherzogs zählten üblicherweise drei Elemente: Die Taufe als religiöses Ritual in der Ritterstube der Wiener Hofburg, ${ }^{27}$ eine dreitägige Festillumination der Stadt Wien direkt nach der Geburt ${ }^{28}$ und der von einem Gottesdienst begleitete „Hervorgang“ der Mutter aus dem Wochenbett rund sechs Wochen nach der Geburt. ${ }^{29}$ Die im Fall der Geburt eines Thronfolgers vorzunehmende

\footnotetext{
${ }^{23}$ HHStA, Zeremonialprotokolle 18 (1741/1742), fol. 28r.

${ }^{24}$ HHStA, Zeremonialprotokolle 18 (1741/1742), fol. 28v.

${ }^{25}$ HHStA, Zeremonialprotokolle 18 (1741/1742), fol. 29r; Wienerisches Diarium, 15. März 1741: Bericht über die Geburt Josephs, von welcher [...] alsogleich der Ruf mithin ein immerwährendes Jubel-Geschrey durch alle Gässen ging.

${ }^{26}$ Gestrich, Absolutismus, 127; Küster, Vier Monarchien, 86.

${ }^{27}$ Beschreibung deren in der königl. Burg zu Wien den 13. Martii 1741. prächtig vollbrachten Tauf-Ceremonien, 9-16.

${ }^{28}$ Bei der Hofkonferenz am 31. Januar 1741 zur Vorbereitung der Taufe wurde festgehalten: und endlichen auch durch 3 Täg in der Stadt eine illumination zu halten, anerwogen ein solche jedesmahlen bey beglükter Erst gebuhrt eines Erzherzogs observiret, und niemahlen unterlassen worden; vgl. HHStA, Zeremonialprotokolle 18 (1741/1742), fol. 15v.

${ }^{29}$ Stöckelle, Geburten, 131-133.
} 
Festillumination, also das Ausschmücken der Häuser mit beleuchteten Sinnsprüchen und Allegorien durch die Bewohner, wurde im „Wienerischen Diarium“ angekündigt, ${ }^{30}$ wodurch das Medienereignis der Geburt zum Teil planbar war. Im Vorfeld waren zudem in den Erblanden Gebete für eine glückliche Niederkunft befohlen worden. Durch diese höfischen Anordnungen partizipierte die Bevölkerung nicht nur am Festereignis der Geburt; ihre Eigeninitiative bei der Huldigung des Herrschers wurde vom Hof explizit eingefordert. ${ }^{31}$

Maria Theresia änderte jedoch diesen traditionellen Ablauf, indem sie die städtischen Illuminationen auf die beiden Tage nach ihrem Hervorgang am 23. April 1741 verschob. ${ }^{32}$ Dadurch konnte sie persönlich an den Festivitäten teilnehmen, die Illuminationen betrachten und sich durch die jubelnde Bevölkerung huldigen lassen. Diese Änderung im traditionellen Festablauf stellte ihre Funktion als Landesherrin vor ihre Rolle als Mutter, denn üblicherweise wurde der Landesherr und Vater durch die Illuminationen verherrlicht. Der Adressat der städtischen Lobpreisung sollte aber in diesem Fall Maria Theresia als Herrscherin sein und nicht Franz Stephan als Mitregent. Aufgrund der Verschiebung des Zeitpunkts der Illuminationen hatten die Bürger und Adeligen mehr Zeit, die Festgerüste durch Maler, Architekten und Bühnenbildner vorbereiten $\mathrm{zu}$ lassen und poetische und allegorische Sinnsprüche zu verfassen. $^{33}$ Die längere Vorbereitungszeit führte $\mathrm{zu}$ einer überproportionalen Zahl an Privatinitiativen. Die über die bloße Präsenzöffentlichkeit hinausgehende Partizipation der Wiener Stadtbevölkerung an der Repräsentation des Herrschers war ein habsburgisches Spezifikum, erlebte in der Regierungszeit Maria Theresias jedoch in quantitativer Hinsicht einen Höhepunkt. Vergleichbare Phänomene sind in anderen Monarchien der Frühen Neuzeit nicht zu finden. Bei der Geburt eines Thronfolgers (Dauphin) im französischen Königshaus beschränkte sich die Feier der Stadt Paris auf ein Feuerwerk und die Ausgabe von Wein und Geld an die Stadtbevölkerung. Lediglich die städtischen Repräsentanten illuminierten und schmückten ihre Häuser und das Rathaus für den König. ${ }^{34}$ Die Einbeziehung der Bevölkerung in dynastische Feste hatte keine Tradition in der französischen Herrscherinszenierung, wurde

\footnotetext{
${ }^{30}$ Der Offentliche Ruf zur Illumination der Stadt erfolgte mehrfach durch das Wienerische Diarium, zuletzt am 22. April 1741.

${ }^{31}$ Die Illumination wurde nicht nur in Wien, sondern auch in anderen Städten anbefohlen. Zu Graz vgl. StLA, Laa. A. Antiquum II. K. 14, H. 89, 17. März 1741; zu Klagenfurt vgl. KLA, Ständisches Archiv, C Akten, Abteilung 1, Schachtel 398, fol. 86r, 14. März 1741; zu Linz vgl. HHStA, Hausarchiv, Ministerium des Inneren, Fasz. 3, Konv. 13, 1. März 1741.

${ }^{32}$ Wienerisches Diarium, 8. März 1741. Bereits am 4. März 1741 wurde die niederösterreichische Regierung von dieser Änderung in Kenntnis gesetzt, vgl. HHStA, Hausarchiv, Ministerium des Inneren, Fasz. 3, Konv. 13, 4. März 1741.

${ }^{33}$ Dietrich, Theater am Hofe, 397.

${ }^{34} \mathrm{Zu}$ Festbeschreibungen anlässlich der Geburten Louis Ferdinands 1729 und Louis Josephs 1781 vgl. Wienerisches Diarium, 24. September 1729 bzw. 10. November 1781 u. 21. Januar 1782.
} 
nicht angestrebt und durch die räumliche Distanz zwischen Stadt und Residenz zusätzlich erschwert.

Parallel zu diesem Festereignis besorgten bildliche und textliche Medien die nachhaltige Implementierung der Nachricht als bedeutungsträchtiges und gemeinschaftsstiftendes Ereignis. Die Quellen über Josephs Geburt sind sowohl Zeugnisse einer breit angelegten Informationsund Gedenkstrategie des Wiener Hofes als auch Beleg einer intensiven Partizipation der Stadtbevölkerung sowie einzelner Initiatoren an der Repräsentation des Herrscherhauses aus Anlass dieses freudigen Ereignisses.

Als das traditionsreichste Medium der Herrscherrepräsentation galt in der Frühen Neuzeit die Medaille. Anlässlich der Geburt Josephs entstanden drei verschiedene vom Hof in Auftrag gegebene Varianten. ${ }^{35}$ Medaillen verdichten komplexe Botschaften auf kleinstem Raum und sind aufgrund ihrer Materialität beständiger als alle anderen Kunstgattungen, was sie zu besonders kostbaren und langlebigen Erinnerungsstücken macht. ${ }^{36}$

Das Medium mit der kürzesten Produktionsphase stellte die Flugschrift dar: Ihre plurimediale Vernetzung von Bild und Text erreichte zudem ein breites Publikum und vermittelte neue Nachrichten mit bekannten ikonografischen Formeln, wodurch Flugschriften über eine überregionale Wirkmacht verfügten. ${ }^{37}$ Ein Beispiel für eine reichhaltige allegorische Verbildlichung ohne Reportagecharakter ist das doppelseitig bedruckte Flugblatt „Cvnalis Honos Votivus [...]“ (Wien, Österreichische Nationalbibliothek, Sammlung von Handschriften und alten Drucken, Flugblättersammlung, F 000377-B).

Die Schabkunstdarstellung zeigt - dem Titel des Blattes entsprechend - die Wiege Josephs unter einem Baldachin mit dem österreichischen Bindenschild anstelle eines Throns. Mit Herrschaftszeichen und Wappen ausgestattete Löwen und Adler, im Text des Huldigungsgedichtes als „Stützen der Wiege“ bezeichnet, versinnbildlichen die Fülle von Josephs ererbten Herrschaftsansprüchen. Das Gedicht erläutert die Ikonografie der Grafik und deren allegorische Anspielungen und vermittelt unter Einbeziehung einer Vielzahl von VergilZitaten in erster Linie die politisch-dynastische Bedeutung des Ereignisses. Eine ähnliche Aussage trifft das in Augsburg verlegte Flugblatt „Das Frohlockende Wien“, in dem Personifikationen von Theologen, Räten, Bauern und Bürgern gemeinsam mit der Stadt Wien

\footnotetext{
${ }^{35}$ Fiala, Katalog, Bd. 2, 242-244. Fiala führt noch drei weitere Stempel auf, zu denen keine Exemplare erhalten sind. Die drei Medaillen werden auch zeitgenössisch beschrieben in Habsburg-Lothringen, Schau- und Denkmünzen, Nr. XVIII-XX.

${ }^{36}$ Vogel, (Selbst-)Inszenierungen, 19.

${ }^{37}$ Vogel, Bildpublizistik, 360.
} 
und der Personifikation der Zeit die Geburt Josephs feiern. ${ }^{38}$ Dieses Flugblatt rezipierte die rege Beteiligung vieler Gruppen an den Wiener Festaktivitäten und transportierte sie in die Medienöffentlichkeit des Heiligen Römischen Reiches.

Die anlässlich Josephs Geburt erschienenen Druckschriften übertrugen ephemere Festereignisse in dauerhafte Medien wie beispielsweise Festreden und Predigten, stellten also Multiplikatoren eines zeitlich und örtlich begrenzten Geschehens dar. Das liegt auch am Charakter einer Geburt, die mit Gottesdiensten, Taufe und Freudenfesten stets ein vorwiegend rituell praktiziertes Kommunikationsereignis darstellt. Diese lokal begrenzt erlebbaren und somit nur einer Präsenzöffentlichkeit unmittelbar zugänglichen profanen und religiösen Feste, darunter Dankgottesdienste, Feuerwerke und ein Theaterstück ${ }^{39}$, wurden erst durch die gedruckten Beschreibungen mit Deutung und Kontextualisierung der Nachricht einer übergreifenden Medienöffentlichkeit zugänglich gemacht und schufen das Medienereignis Geburt. $^{40}$

Die wichtigste Verbindung zwischen vergänglichen Festen und dauerhafter Überlieferung stellten die ebenfalls in habsburgischer Tradition stehenden „Wiennerischen Beleuchtungen“ dar. ${ }^{41}$ Das umfangreiche Druckwerk präsentierte eine vom Hofbuchdrucker van Ghelen zusammengetragene und verlegte Sammlung der Illuminationen und Sinnsprüche, die anlässlich von Maria Theresias Hervorgang am 23. April 1741 in Wien zu sehen waren. ${ }^{42}$ Die rund 320 Seiten umfassende Beschreibung der Ehrengerüste, leider ohne Abbildungen, führt etwa 250 Illuminationen an Gebäuden aus allen Bevölkerungsschichten auf. Das Freudengerüst, das der Architekt Franz Rosenstingel (Rosenstiengl) (1702-1785) gemeinsam mit Martin van Meytens dem Jüngeren (1695-1770) im Auftrag der Stadt Wien errichtete, war immerhin 30 Meter hoch und 20 Meter breit, mit allegorisch und mythologisch ausgerichteter Malerei und tausenden Wachslichtern geschmückt. ${ }^{43}$ Von einer Musikempore ertönten Pauken und Trompeten, während aus den Brunnen roter und weißer Wein für die Bevölkerung floss. Diese prachtvolle ephemere Inszenierung ist eines der wenigen Freudengerüste, die durch einen Stich verewigt wurden. ${ }^{44}$ Zur Erläuterung des allegorischen Programms der über dem

\footnotetext{
${ }^{38}$ Steißlinger [Stecher und Verleger], Das frohlockende Wien. Hingegen bezieht sich Elias Baecks (Augsburg) Stich mit dem Titel „Hoch Feyerliche Tauff Acts Vorstellung [...]“ (Wien, Albertina, Historische Blätter, Bd. 8, Umschlag Joseph II., DG 2005/10313) auf die Zeremonie selbst.

${ }^{39}$ Im Kärntnertortheater wurde die Oper „Die glückliche Vorbedeutung“ aufgeführt; vgl. Dietrich, Theater am Hofe, 397.

${ }^{40}$ Vgl. die Einleitung dieses Beitrags; zur Methode siehe Rudolph, Das Reich als Ereignis, 332.

${ }^{41}$ Anlässlich der Geburt von Erzherzog Leopold Joseph wurden 1716 die ersten „Wienerischen Beleuchtungen“ herausgegeben: Beschreibung Der Sinn-Bildern.

${ }^{42}$ Wiennerische Beleuchtungen.

${ }^{43}$ Prange, Freudengerüst, 168.

${ }^{44}$ Freudengerüst anlässlich der Geburt Josephs II., 1741, Wien Museum Inv.-Nr. 31459, Stich von Salomon Kleiner.
} 
Tugendtempel aufgehenden Aurora und der Inschriften erschien eine Huldigungsschrift in antiker panegyrischer Tradition. ${ }^{45}$ Demgegenüber standen einfache Illuminationen von Bürgerhäusern mit schlichten Sinnsprüchen wie Es lebe des Prinzens Frau Mutter die Resel [scil. Maria Theresia] ${ }^{46}$ am Haus eines Färbers. Viele Bürger verbanden die Huldigung an die Monarchin mit Werbung für das eigene Geschäft, wie etwa der Perückenmacher Palmberger, der wünschte, Er leb so viele Jahr / Als in der ganzen Welt Perucken-Macher-Haar, ${ }^{47}$ oder das Wirtshaus „Zum schwarzen Bären“: Der Wein wachst nicht für uns, doch trincken wir heut Weinn / Und muß des kleinen Prinzen Gesundheit trunken seyn. ${ }^{48}$ Das Stadtfest war nicht nur gemeinschaftsstiftend, sondern wahrscheinlich auch wirtschaftlich profitabel, wodurch auch die überproportionale Partizipation der nichtadeligen Bevölkerung erklärt werden kann. Ikonografie, Themen und Diskurse wiederholten sich in den Huldigungsschriften und Sinnsprüchen und lassen Rückschlüsse auf Stimmungen und Meinungen bzw. entsprechende Konstruktionen zu. Vergleicht man die Sinnsprüche adeliger Auftraggeber mit jenen der Bürger wird deutlich, dass die Rechtmäßigkeit von Maria Theresias Thronfolge in der einfachen Bevölkerung der Erblande eher angezweifelt wurde, auch wenn selbstverständlich keine deutlich formulierte Kritik zu finden ist. Diese Zweifel wurden nur unterschwellig kommuniziert, beispielsweise legitimiere erst der Thronfolger Joseph die Durchsetzung ihrer Herrschaftsansprüche in Böhmen und Ungarn, so der Tenor mancher Quellen. ${ }^{49}$ In einer publizierten Festrede der Kärntner Landstände wurde Maria Theresia sogar nur im Titel erwähnt; als Landesfürstin spielte sie keine Rolle. ${ }^{50}$

Der bekannte Wiener Jesuit und Domprediger Franz Peikhardt (Peickhardt bzw. Peikhart) (1684-1752), ${ }^{51}$ der am Sonntag nach der Geburt eine anschließend publizierte Predigt in St. Stephan in Wien hielt, griff die naheliegende Anspielung auf den Namen Joseph als Nährvater Jesu und Beschützer Marias auf und betonte gleich zu Beginn, dass Österreich durch einen männlichen Fürsten errettet worden sei. ${ }^{52}$ Dadurch wurde Maria Theresia in die Rolle einer Regentin für ihren unmündigen Sohn versetzt und nicht als legitime Erbin Karls VI. dargestellt. Die Argumentation nahm Bezug auf den weiblichen Tugendkanon, dem zufolge eine Frau nicht aus eigenem Interesse, sondern nur als Mutter für ihren Sohn Macht und Herrschaft anstreben

\footnotetext{
${ }^{45}$ P. L. C. V. H., Sonne.

${ }^{46}$ Wiennerische Beleuchtungen, 157.

${ }^{47}$ Wiennerische Beleuchtungen, 219.

${ }^{48}$ Wiennerische Beleuchtungen, 128. Ähnliche Sprüche fanden sich auch am Hof-Wirtshaus; vgl. Wiennerische Beleuchtungen, 304.

${ }^{49}$ Besonders deutlich in: Allgemeines Frolocken, Vers 11-14.

${ }^{50}$ Richter, Morgen-Stern.

${ }^{51}$ Old, Reading, $344 \mathrm{f}$.

${ }^{52}$ Peikhardt, Wunsch und Hoffnung, 5.
} 
dürfe. In der Verherrlichung Maria Theresias dominierten stattdessen charakterliche Zuschreibungen wie Sanftmut und Frömmigkeit, die insbesondere in der jesuitischdialektischen Rhetorik als ideale weibliche Tugenden klassifiziert wurden. ${ }^{53}$ Diese Assoziationen entsprachen jedoch nicht den klassischen Eigenschaften einer starken Führungsperson.

Josephs Funktion und Aufgabe sei es, für seine Mutter zu kämpfen, weshalb er in vielen Sinnsprüchen explizit die Rolle eines neuen Herkules einnahm. ${ }^{54}$ Gerade die Herkulesmythologie im Sinne ihrer Instrumentalisierung als politische Ikonografie war seit Kaiser Leopold I. (1640-1705) in der habsburgischen Herrscherrepräsentation äußerst präsent. ${ }^{55}$ Im Zuge der Geburt Josephs ist das Motiv des jungen Helden, der aus der Wiege heraus Schlangen erwürgt und seine Feinde besiegt, demgemäß ein naheliegender und daher verbreiteter Topos. Er wurde nicht nur von den Bürgern und Huldigungsautoren verwendet, sondern auch auf eine vom Hof in Auftrag gegebene Medaille geprägt. ${ }^{56}$ Weitere beliebte Anspielungen auf Joseph waren der Adler ${ }^{57}$, der Schiffsanker ${ }^{58}$ (als Symbol der Hoffnung) oder Aeneas als Stammhalter. ${ }^{59}$ Der Bruch der männlichen Thronfolge wurde symbolisch durch einen Stammbaum mit verdorrten Ästen dargestellt, der mit Joseph nun einen neu erblühenden Zweig trug. Das Aussterben der männlichen Linie der Habsburger war durchgehend präsent, spielte jedoch in den Druckschriften, die in den Reichsstädten verlegt wurden, ${ }^{60}$ eine deutlich größere Rolle als in den Erblanden, da die kaiserliche Nachfolge im reichspolitischen Diskurs viel gegenwärtiger war. ${ }^{61}$ Auf einer in Nürnberg in Eigeninitiative geprägten Medaille wurde die Verbindung der Häuser Habsburg und Lothringen durch den gemeinsamen Sohn versinnbildlicht. $^{62}$ Die Auseinandersetzung mit der neu gegründeten Dynastie im Zusammenhang mit Josephs Geburt war somit ein reichsspezifischer Diskurs, der sich von den Deutungen in den Österreichischen Erblanden aufgrund der unterschiedlichen politischen Perspektive unterschied.

\footnotetext{
${ }^{53}$ Mauser, Maria Theresia, $142 \mathrm{f}$.

${ }^{54}$ Etwa am Wiener Stadthaus des Abtes von Göttweig in der Herrengasse: Wiennerische Beleuchtungen, 49;

P. L. C. V. H., Sonne, 5.

${ }^{55}$ Matsche, Caesar et Imperium, 51; vgl. auch Beschreibung Der Sinn-Bildern, Vorwort.

${ }^{56}$ Fiala, Katalog, Bd. 2, 242; Habsburg-Lothringen, Schau- und Denkmünzen, Nr. XIX.

${ }^{57}$ Etwa an der Karlskirche: Wiennerische Beleuchtungen, 66.

${ }^{58}$ Allgemeines Frolocken, Vers 3.

${ }^{59}$ Vgl. Geelhaar, Maria Theresia, 163.

${ }^{60}$ Chareß, Der Tag, 2; laut Angabe auf dem Titel hat Chareß Maria Theresia diese Schrift am Tag ihres Hervorgangs persönlich überreicht.

${ }^{61}$ Hackmann, Die Höchst-glückliche Geburt. Obwohl diese Huldigung in Wien verlegt wurde, stammt Hackmann aus Berlin und Halle und kam erst 1734 als Hochschullehrer nach Wien. Er kann somit trotzdem dem Diskursraum des Reiches zugerechnet werden; vgl. GND: http://d-nb.info/gnd/116354313 [Zugriff: 18.05.2016]. ${ }^{62}$ Peter Paul Werner (Medailleur und Verleger), Medaille auf die Geburt von Erzherzog Joseph, Nürnberg 1741; vgl. Fiala, Katalog, Bd. 2, 242; Habsburg-Lothringen, Schau- und Denkmünzen, Nr. XVIII.
} 
Der Zeitpunkt der Geburt spielte ebenfalls eine dominante Rolle in allen Huldigungsmedien, denn Zufälle und Umstände wurden als Zeichen göttlicher Gunst gedeutet. ${ }^{63}$ Da Joseph sowohl kurz vor Sonnenaufgang als auch vor Frühlingsbeginn zur Welt kam, wurde er als aufgehende Sonne verherrlicht, die Winter, Krieg und Finsternis verjage. ${ }^{64}$ Die Sonnenmetaphorik ist in der europäischen Herrscherikonografie seit Ludwig XIV. von Frankreich ${ }^{65}$ (1638-1715) weit verbreitet und fand auch bei der Geburt Erzherzog Leopolds (1716) und Erzherzog Leopold Josephs (1682) Anwendung. ${ }^{66}$ In der symbolischen und mythologischen Verherrlichung von Josephs Geburt wurden sowohl spezifisch habsburgische als auch europaweit verbreitete Herrschaftstopoi verwendet. Ikonografische Neuschöpfungen fanden nicht statt; es lässt sich vielmehr von Umdeutungen und Neuinterpretationen sprechen.

Ein thematisch mit Josephs Geburt verbundenes, aber nicht mehr direkt zum Medienereignis gehörendes Fest fand erst im Herbst 1743 statt, ein Freuden-Schießen der Bürgerschaft. Die Beschreibung dieses zweiwöchigen Festereignisses, die Teilnehmerlisten und Ergebnisse wurden ebenso wie die Stiche der Schießscheiben von van Ghelen publiziert. ${ }^{67}$ Eingefügt war eine Ansprache des Wiener Bürgermeisters Peter Joseph Kofler (1700-1764) an Maria Theresia, in der er sie mit der Amazonenkönigin Penthesilea verglich, deren Schönheit und Heldenhaftigkeit er auch an ihr rühmte. ${ }^{68}$ In der Zwischenzeit hatte Maria Theresia Prag zurückerobert und war zur böhmischen Königin gekrönt worden, wodurch sie ihre Herrschaftsbefähigung noch deutlicher als allein durch Josephs Geburt demonstriert hatte. Der zitierte Vergleich mit der mythologischen Figur einer kämpfenden Königin lässt daher auf eine Entwicklung in der Wahrnehmung von Maria Theresias Herrschaft schließen. Ihr Lobpreis war nun nicht mehr einzig auf weibliche Tugenden reduziert, sondern ihr wurden auch vornehmlich männlich konnotierte Tugenden wie Kriegsgeschick, Macht und Führungsstärke attestiert.

Die höfischen Strategien in Bezug auf Öffentlichkeit im Rahmen dynastischer Feste im 17. und 18. Jahrhundert lassen sich Bernd Sösemann zufolge in vier Phasen unterteilen, die auch bei Josephs Geburt zu beobachten sind: Ankündigung, Berichterstattung, Einbeziehung des Publikums und Nachhaltigkeit. ${ }^{69}$ Demzufolge ist die Geburt Josephs als teilweise ankündbares dynastisches Geschehen mit großer politischer Tragweite einzuordnen, das mittels höfischer Impulse zum Medienereignis erweitert wurde. Während die Veröffentlichung der Nachricht ein

\footnotetext{
${ }^{63}$ Garstka, Herrscherlob, 42.

${ }^{64}$ Vgl. Cvnalis Honos Votivus; Richter, Morgen-Stern, 2; P. L. C. V. H., Sonne, 2.

${ }^{65}$ Hengerer, Ludwig XIV.

${ }^{66}$ Vgl. Reiffenstuel, Wiennerischer Stadt-Danck, 4; Polleroß, Architektur und Panegyrik, 380.

${ }^{67}$ Beschreibung des Haupt- und Freuden-Schießens.

${ }^{68}$ Beschreibung des Haupt- und Freuden-Schießens, $21 \mathrm{f}$.

${ }^{69}$ Vgl. Sösemann, Zeremoniell, 86.
} 
europaweit wahrgenommenes Kommunikationsereignis ${ }^{70}$ darstellte, spielte sich das Medienereignis hauptsächlich im habsburgischen Einflussbereich ab. Wien nahm als Residenzstadt in Bezug auf die Präsenzöffentlichkeit einen besonderen Stellenwert ein, weil die städtische Illumination nicht nur als eigenständiges, anlassbezogenes Fest gewertet werden kann, sondern Maria Theresia als Adressatin der Verherrlichung die Beleuchtungen persönlich besuchte. Durch die Drucklegung der Beleuchtungsbeschreibungen wurden die Handlungen und Botschaften der Präsenzöffentlichkeit multipliziert und erreichten die übergeordnete Medienöffentlichkeit der Erblande und des Reiches, insbesondere die habsburgisch geprägten süddeutschen Reichsstädte. Wichtig ist hier festzustellen, dass die Druckschriften in erster Linie die Festivitäten und ihren Ablauf beschrieben, nicht jedoch den Geburtsakt selbst, der somit seinen dezidiert nichtöffentlichen Charakter auch in der Medialisierung behielt. Die zweite Funktion der Druckschriften war die Interpretation der politischen und dynastischen Bedeutung der Geburt des Thronfolgers. Diese erfolgte mithilfe einer historischen Einordnung, indem auf das Aussterben des Hauses Habsburg im Mannesstamm und den Tod Erzherzog Leopold Johanns (1716) verwiesen und so an das kollektive Gedächtnis der Leser appelliert wurde. ${ }^{71}$ Insofern war die Geburt Josephs kein erst von den Medien „gemachtes“ Ereignis, das Medienereignis reflektierte und multiplizierte jedoch ihre Bedeutsamkeit.

Durch die mediale Berichterstattung und die Handlungsaufforderungen an die Bevölkerung sowohl im Vorfeld als auch begleitend - wurde die Geburt Josephs zum gemeinsamen Schicksal von Herrscherin und Untertanen stilisiert und die Partizipation unterschiedlicher Bevölkerungsgruppen an den verschiedenen Etappen des Fest- und Medienereignisses gleichermaßen anbefohlen und forciert. Die landesweiten Gottesdienste, Gebete und Feste mit ihrem integrativen Charakter waren Mittel der Herrschaftssicherung und -stabilisierung in der politisch wie militärisch brisanten Anfangsphase von Maria Theresias Regierung, und die überproportionale Beteiligung der städtischen Bevölkerung an ihrer Verherrlichung stellte eine machtvolle Inszenierung dar, die sich gegen ihre europäischen Feinde richtete.

Die Geburt als ein höfisch-dynastisches Ereignis zählte unabhängig vom politischen Kontext zum Bereich der „sichtbaren“ Politik, über die unverfängliche Berichterstattung aufgrund der übereinstimmend positiven Wertung dieses Ereignisses möglich war. ${ }^{72}$ Entsprechend „ritualisiert“ war die mediale Rezeption des Ereignisses durch die Akteure der Medienproduktion: Anlässlich der Geburt Josephs gab der Hofbuchdrucker van Ghelen zusätzlich zu den Nachrichten im „Wienerischen Diarium“ aus eigenen wirtschaftlichen

\footnotetext{
${ }^{70}$ Zu diesem Begriff vgl. Rudolph, Das Reich als Ereignis, 332.

${ }^{71}$ Sösemann, Zeremoniell, 125; Wiennerische Beleuchtungen, 4.

${ }^{72}$ Arndt, Herrschaftskontrolle, 85.
} 
Interessen drei Sonderausgaben heraus: eine Beschreibung der Taufe, eine Beschreibung der „Wiennerischen Beleuchtungen“ sowie eine Publikation über das Schießfest des Jahres 1743. Letztere hätte er sicher nicht verlegt, wenn die ersten beiden Publikationen keine Gewinne eingebracht hätten, sodass ein reges öffentliches Interesse am Medienereignis der Geburt konstatiert werden kann.

Die meisten Huldigungsautoren waren in dem Hof nahestehende Institutionen eingebunden wie etwa der Stadtrat des Wiener Magistrats, der unter seinen Initialen P. L. C. V. H. publizierte. Er hatte bereits eine ausführliche Beschreibung der niederösterreichischen Erbhuldigung im November 1740 verfasst, die ohne Nennung eines Verlags erschienen war. ${ }^{73}$ Offenbar hatte diese Initiative das Wohlwollen des Hofes erfahren und war auch wirtschaftlich profitabel gewesen, sodass van Ghelen den Druck seiner nächsten Schrift übernahm. Auch der Jesuit Franz Peikhardt war bereits mehrfach als Prediger im Zusammenhang mit höfisch-dynastischen Ereignissen in Erscheinung getreten. ${ }^{74}$ Seine Ausführungen wurden im erzbischöflichen Verlag Heyinger gedruckt, der auch zwei weitere Huldigungen mit Genehmigung des Hofes verlegte. Die Partizipation kirchlicher Institutionen und Personen an Medienereignissen ist typisch für sämtliche frühneuzeitliche Monarchien, insbesondere im Zusammenhang mit Geburten und den dazugehörigen religiösen Begleitritualen. Hier erfüllte die Kirche ihre traditionelle Rolle im Rahmen der dynastischen Frömmigkeitsinszenierung und der Mahnung und Handlungsanweisung an den guten Herrscher. ${ }^{75}$

Von den zwar dem Hof nahestehenden, aber dennoch privat agierenden Huldigungsautoren und Verlegern zu unterscheiden sind die expliziten Öffentlichkeitsstrategien des Hofes im Kontext von Josephs Geburt. Diese konzentrierten sich vor allem auf die Verbreitung der Nachricht und die Anweisung von Festen in den Erblanden, wodurch der Hof seine Absicht unterstrich, dem Ereignis Bedeutung zu verleihen. Anschließend verließ sich der Hof auf bereits bestehende Strukturen der Herrscherhuldigung durch die mit ihm verbundenen Institutionen und einzelnen Akteure, die ihre Rollen der Tradition entsprechend erfüllten. Dennoch gab der Wiener Hof die Deutungshoheit über das Ereignis nicht ab: Zum einen gab er durch die Prägung der Medaillen seine eigene Deutung der Geburt vor, ${ }^{76}$ zum anderen garantierte er durch die Zensur und die Vergabe von Publikationsgenehmigungen eine Huldigungspublizistik in seinem Sinne. ${ }^{77}$

\footnotetext{
${ }^{73}$ P. L. C. V. H., Tod.

${ }^{74}$ Z. B. Peikhardt, Ehren-Rede.

75 Schneider, La Monarchia, 116.

${ }^{76}$ Zur Überlieferung der Medaillen-Stempel, die im Auftrag des Hofes entstanden, vgl. Fiala, Katalog, Bd. 2, 242.

${ }^{77}$ Über die Zensur seiner Publikation berichtete van Ghelen in der Einleitung zu den „Wiennerischen Beleuchtungen“: Welche übrigens ihre Sinn-Bilder entweder hier gar nicht / oder doch in etwas verändert antreffen werden / müssen die Schuld hiervon nicht auf den Zusammen-trager legen / als der hierinnen nach
} 


\section{Der erste Sieg gegen Friedrich II.: Die Schlacht bei Kolín 1757}

Seit dem späten 17. Jahrhundert gewann die Darstellung von Kriegsereignissen - befördert durch die Zweite Türkenbelagerung (1683), die darauffolgenden Auseinandersetzungen mit den Osmanen sowie den Spanischen Erbfolgekrieg - eine zunehmende Bedeutung, und dies vor allem im Rahmen der Druckgrafik sowie auf Medaillen. Einem Trend folgend, der sich zum ersten Mal im Österreichischen Erbfolgekrieg und im Siebenjährigen Krieg manifestierte, produzierten vor allem die süddeutschen Verlegerzentren Augsburg und Nürnberg massenhaft Schlachtenszenen sowie schematische Darstellungen der konkreten Positionen militärischer Verbände, ohne dass dies als Charakteristikum einer spezifischen (habsburgischen) Art bildlicher Repräsentation angesehen werden könnte.

Hier zeigt sich bereits in anschaulicher Weise, dass Kriege - so eigenartig dies auch klingen mag - besonders „kommunikationsverdichtend““78 wirken: Sie produzieren jene Ereignisse, die dann in der Folge in unterschiedlichen medialen Formaten verbreitet werden. Unter den Schlachten des Siebenjährigen Krieges nimmt jene von Kolín (1757) eine historische Sonderstellung ein, da in ihr Friedrich II. zum ersten Mal bezwungen wurde: Feldmarschall Leopold Joseph Graf von Daun (1705-1766) eilte mit einem Entsatzheer nach Prag, um den dort eingeschlossenen österreichischen Truppen zu Hilfe zu kommen. Der Preußenkönig brach daraufhin die Belagerung Prags ab und griff die Österreicher trotz zahlenmäßiger Unterlegenheit an. Nach mehreren Stunden gelang es der österreichischen Armee, die desorientierten Preußen entscheidend zurückzuschlagen. Diese epochale militärische Begegnung lieferte auch einer prominenten Persönlichkeit der österreichischen Seite, nämlich Feldmarschall Daun, erstmals die Gelegenheit, sich als „selbständiger Befehlshaber eines größeren Heeres in der Schlacht zu bewähren““79, was sich in der Folge auch in einer Fülle von Lobschriften auf ihn äußerte, ${ }^{80}$ wie sie sonst nur für Ernst Gideon Laudon (1717-1790) nachzuweisen ist. ${ }^{81}$ Dieser signifikante Umstand ist auch an der Berichterstattung ablesbar, da es für die Medialisierung gerade dieser Schlacht charakteristisch zu sein scheint, dass die Propaganda auf eine deutliche Personalisierung zielt, die eben in der Verherrlichung Dauns am deutlichsten wird, dem abwechselnd mit Maria Theresia die Heldenrolle zugeschrieben wird. Als entsprechende Beispiele dafür fungieren das offizielle (gedruckte) Dankschreiben der

\footnotetext{
höherer Anordnung sich richten / und das jenige auslassen müssen / darinnen die unbeschränkte Freud die Gränzen des schuldigsten Respects / und geziehemender Ehrbarkeit überschritten / oder solche sonst bedenklich aufgenommen worden. Vgl. Wiennerische Beleuchtungen, 4.

${ }^{78}$ Dainat, Der Siebenjährige Krieg, 17.

${ }^{79}$ Wenzlik, Kolin, 103.

${ }^{80}$ Z. B. HHStA, Hausarchiv, Familienakten, 110, Fasz. 23 (Kurze Trostschrift für das klagende Oesterreich); weitere Schriften in HHStA, Sonderbestände, Flugschriften, 5 (1755-1810).

${ }^{81}$ Vgl. Kunisch, Laudons Nachruhm.
} 
Monarchin an Daun vom 22. Juni 1757, die „Mythisierung“ des Sieges als „Geburtstag der Monarchie“ ${ }^{82}$, der Beginn eines dreitätigen Dankgebets ab dem 21. Juni 1757, ${ }^{83}$ die überaus rasch erfolgte Gründung des Militär-Maria-Theresien-Ordens, ${ }^{84}$ dessen visuelle Propagierung durch Martin van Meytens den Jüngeren (um 1763) in einem im heutigen Billardzimmer von Schloss Schönbrunn befindlichen Gemälde und die alljährlich bei den Wiener Augustinern am Jahrestag der Schlacht abgehaltenen Dankesfeste. ${ }^{85}$ In bisher ungekannter Weise schien man also am Hof bzw. bei den von dort abhängigen Verlegern nur darauf gewartet zu haben, einen militärischen Sieg rasch und umfassend propagieren respektive instrumentalisieren zu können. Kolín fungiert aber zugleich als Beispiel für einen Schlachtensieg, der auf beiden Seiten eine massive Gedenkkultur produzierte: Hier wären die Rezeption der Schlacht in den berühmten Soldatenlieder Johann Wilhelm Ludwig Gleims (1719-1803) aus dem Jahr 1758, ${ }^{86}$ die um 1758 erfolgte Erwähnung in Jan František Vaváks (1741-1816) tschechischem Gedicht sowie ihre Rezeption in zahlreichen Volksliedern ${ }^{87}$ zu nennen.

Hinsichtlich der Medien, die dieses Ereignis thematisieren, ist zwischen ungedruckten (Kabinettschreiben, Relationen, Journals etc.) und gedruckten (Schlachtenszenen, Schlachtpläne und Schlachtbeschreibungen) Text (bzw. Bild-)quellen sowie anderen Bildmedien (vor allem Gemälde und Medaillen) zu differenzieren. Essentiell ist dabei das Faktum, dass jedes Medium bestimmte Funktionen bei der Konstruktion des Schlachtenereignisses von Kolín zu erfüllen hatte, hier also ein dezidiert arbeitsteiliges System vorliegt. Als grundlegend kann hier somit die „Bedeutung medialer konkret: gattungsspezifischer Eigenheiten“ ${ }^{88}$ festgehalten werden: Streng auf die Wiedergabe der militärischen Aktionen reduziert sind die „Journals“ ${ }^{89}$ Ebenfalls den militärischen Hintergrund betreffen die „Relationen“, die das Geschehen vorwiegend aus der Distanz beschreiben. ${ }^{90}$ Zudem existieren gedruckte Kriegschroniken in mehrbändiger Form: Hier sind etwa Christoph Gottlieb Richters illustrierte sechsbändige „Historie des Kriegs zwischen den Preußen und ihren

\footnotetext{
${ }^{82}$ Broucek, Geburtstag der Monarchie, 125; vgl. hier das Kabinettschreiben vom 21. Juni 1757 an Daun (HHStA, Kriegsakten, 358 [1757-1763], Fasz. alt 416, fol. 113-118).

${ }^{83}$ HHStA, Zeremonialprotokolle 26 (1757/1758), fol. 80-82.

${ }^{84}$ Vgl. das Handschreiben Maria Theresias an Daun vom 22. Juni 1757: HHStA, Kriegsakten 358 [1757-1763], Fasz. alt 416, fol. 119-130.

${ }^{85}$ AVA, Kriegsarchiv, ZSt HKR SR KzlA XIII, 158 (Kontrakt mit den Augustinern an der Hofpfarrkirche wegen des jährlichen Dankfestes im Gedenken an den Sieg bei Kolín); vgl. grundsätzlich zur Medialisierung der Erinnerung an den Siebenjährigen Krieg Füssel, Erinnerung.

${ }^{86}$ Zur Struktur dieser Lieder, die eine emotionale Hinwendung erzeugen sollten und bewusst ausschließlich die Vornamen der Herrscher wie Theresia und Friedrich verwenden, vgl. Jahn, Medialität, 99 f.

${ }^{87}$ Broucek, Geburtstag der Monarchie, $165 \mathrm{f}$.

${ }^{88}$ Emich, Bilder einer Hochzeit, 220.

${ }^{89}$ Grundsätzlich: Anklam, Wissen.

${ }^{90}$ Weißbrich, Höchstädt, 161 f.
} 
Bundgenossen und den Österreichern“ ${ }^{91}$, der mit zahlreichen Kupferstichen ${ }^{92}$ versehene „Schauplatz des gegenwärtigen Kriegs“ und Johann Wilhelm von Archenholz’ ebenfalls illustrierte $^{93}$ „Geschichte des Siebenjährigen Krieges“ zu nennen.

Aus habsburgischem Blickwinkel gewinnen vor allem Michael Denis’ (1729-1800) „Poetische Bilder der meisten kriegerischen Vorgänge“ “94 eine besondere Bedeutung: Dieses Werk nimmt als „Kriegslyrik für gebildete Stände“ 95 nicht nur die Destruktion preußischer Legenden vor, sondern ist auch der „Versuch der Konstruktion österreichischer Helden, ja österreichischer Gegenmythen“96. Im Siebenjährigen Krieg ist generell eine „Intensivierung von Flugschriftenpublizistik und Zeitungsberichterstattung“ ${ }^{\text {97 }}$ zu beobachten. Der Vorteil vor allem der Zeitungsproduktion bestand offensichtlich in der Existenz ausgeprägter Korrespondentennetzwerke sowie im periodischen Erscheinen dieses Mediums: ${ }^{98}$ Das jeweilige Ereignis konstituierte sich hier „aus einzelnen Meldungen, die sich von Ausgabe zu Ausgabe entwickelten, jedoch keine verbindliche und geschlossene Erzählung ausbildeten“99. Der „moderne Ereignisbegriff“ ${ }^{100}$,

wie er sich hier wohl deutlich manifestiert, zielt somit auf eine potenziell stets überholbare Aktualität, die tendenziell als unabgeschlossen zu bezeichnen ist, da jede neue Meldung eine alte - vor allem im wechselvollen Militärgeschehen - rasch zu überholen imstande ist. Manfred Schort hat in seiner materialreichen Untersuchung deutlich gemacht, dass zur Zeit des Siebenjährigen Krieges ein „informationshungriges Publikum“101 existierte, das unterrichtet werden wollte und bei den handelnden Parteien offensichtlich das Bewusstsein förderte, dass die öffentliche Meinung beeinflusst werden konnte und sollte.

Die Medienproduktion in Bezug auf die visuelle Wiedergabe von Schlachten lässt sich grundsätzlich in jene Zeugnisse aufteilen, welche die Komplexität militärischer Auseinandersetzungen entweder in einer fiktiven Totalität umzusetzen versuchen oder aber reduzieren; für erstere stehen unter anderem Ölbilder, Panoramen, Dioramen etc., für letztere die Schlüsselszenen historischer Referenzbilder, Selbstzeugnisse und Anekdoten. ${ }^{102}$

\footnotetext{
${ }^{91}$ Richter, Historie des Kriegs.

${ }^{92}$ Jahn, Medialität, 99.

${ }^{93}$ Meier, Buchillustration, 77-82; Jahn, Medialität, 107-110.

${ }^{94}$ Denis, Poetische Bilder der meisten kriegerischen Vorgänge; vgl. dazu auch Birgfeld, Kriegspoesie.

${ }^{95}$ Birgfeld, Kriegspoesie, 237.

${ }^{96}$ Birgfeld, Kriegspoesie, 233, 238 f. (mit Zitaten in Bezug auf Maria Theresia).

${ }^{97}$ Füssel, Evidenz; vgl. grundlegend Schort, Politik.

${ }^{98}$ Weißbrich, Höchstädt, 160.

${ }^{99}$ Weißbrich, Höchstädt, 160.

${ }^{100}$ Weißbrich / Carl, Präsenz, $89 \mathrm{f}$.

101 Schort, Politik, 463.

102 Füssel, Evidenz.
} 
Quantitativ dominierend sind in Bezug auf die Bildquellen die Karte und das Überschaubild. ${ }^{103}$ Zudem können grundsätzlich zwei inhaltliche Herangehensweisen konstatiert werden: die sachliche Kriegsberichterstattung sowie die bewusste Emotionalisierung des Publikums mit künstlerisch aufbereiteten Bildern und Texten.

Ohne Zweifel herausragend in Bezug auf die bildliche Aufbereitung der Schlacht ist die kleinformatige Druckgrafik, die aber in der Regel nicht ohne erklärende Textlegenden auskommt. Dies unterstreicht die generelle Tatsache, dass das (bildliche) Flugblatt und die Flugschrift miteinander in engstem funktionalen Zusammenhang stehen. Sie „ergänzen und bestätigen einander“104, bzw. Bild und Text formen einen gleichsam komplementären Zusammenhang ${ }^{105}$ in Form eines Medienverbundes, der entweder so organisiert sein kann, dass die Textlegende eine allgemein gehaltene Darstellung der jeweiligen Schlacht präzisiert ${ }^{106}$ oder ein enges Abhängigkeitsverhältnis zwischen Bild und darauf verweisender Legende vor Augen führt. ${ }^{107}$

Im konkreten Fall dieses Blattes aus dem Wien Museum ist die Text-Bild-Relation so organisiert, dass die Aufgabe der anschaulichen Accurate[n] Vorstellung ${ }^{108}$ die an der linken Seite angebrachte ausführliche Legende (Umständliche Nachricht von dieser Bataille) mit den Legenden A bis D übernimmt, die bildliche Darstellung hingegen als Simultanbild aufgebaut ist. Letzteres vermittelt die zeitlich eigentlich aufeinander folgenden Handlungssequenzen in Gestalt einer summarisch organisierten Überschauszene. In den meisten Darstellungen sind es allerdings die nichtmilitärischen Gesichtspunkte, welche den Aufbau der Szenerie bestimmen und primär „ästhetische[n] Grundprinzipien“109 folgen. So sollte etwa die „Zeichenhaftigkeit der Schlachtordnung“"110 auf generelle und übergreifende Ordnungsprinzipien verweisen.

Im Gegensatz zu anderen historischen Geschehnissen ist eine Schlacht in ihrer Totalität bzw. aufgrund der Vielzahl unterschiedlicher Akteure kaum adäquat medial zu fassen: Dieser faktischen Undarstellbarkeit kriegerischer Auseinandersetzungen versuchte man mit einer „Vielzahl von Darstellungsmodi““111 zu begegnen: Wahrnehmungen der Schlacht können demgemäß in den traditionellen (erhöht positionierten) „Feldherrenblick“ und viele Einzelwahrnehmungen von Soldaten zerfallen. ${ }^{112}$ Undarstellbarkeit sowie Unbeschreibbarkeit

\footnotetext{
103 Schumacher, Der Siebenjährige Krieg, 246.

${ }^{104}$ Tschopp, Rhetorik des Bildes, 82, 95.

105 Tschopp, Rhetorik des Bildes, 94.

106 Z. B. Kupferstich des Augsburgers Johann Martin Will (Wien Museum, Inv.-Nr. 220.161).

107 Z. B. unsignierter Kupferstich im Wien Museum (Inv.-Nr. 220.163).

108 So der Beginn des Blatttitels in der Kartusche rechts unten.

${ }^{109}$ Rudolph, Lepanto, 109, 111, Abb. 3.

${ }^{110}$ Rudolph, Lepanto, 113.

${ }^{111}$ Füssel, Das Undarstellbare, 320.

${ }^{112}$ Füssel, Das Undarstellbare, 322.
} 
der Totalität einer Schlacht ${ }^{113}$ entfalteten in diesem Sinn eine ganz eigene Vielfalt von mitunter auch konkurrierenden Bildern. ${ }^{114}$ Bereits im bloßen bildökonomischen Sinn hatte eine mediale Zerlegung einer Schlacht in einzelne „Wahrnehmungsfragmente“115 zu erfolgen, um eine Vermittlung von Geschehenssequenzen überhaupt erst möglich zu machen.

Gedruckte Jubeloden, wie die von einem mit N. C. bezeichneten Autor signierte „Ode auff den grossen Sieg, welchen Seine Kayserliche Königliche Majestaet Maria Theresia den 18ten und 20ten Junii dieses 1757ten Jahrs bey Planian und Prag über die Preußische Armée erfochten“116 zeigen grundsätzlich eine starke Bezugnahme auf die recht persönlich als Theresia adressierte Herrscherin, die in ein unmittelbares Verhältnis zu Gott und die sich für die Regentin opfernden Soldaten gestellt wird. Auch jene Oden, die im Reich die Kunde des Sieges verbreiteten, sind stark religiös unterlegt und verfolgen - wie etwa eine unpaginierte „Jubel-Ode auf den am 18ten Junii 1757 [...] ohnweit Planian erfochtenen herrlichen Sieges“ - das Ziel, sich emotional mit der durch Gott gesegneten Siegerin (Gott ist mit Dir Theresia!) zu identifizieren. Der militärische Erfolg ist hier das logische Ergebnis göttlichen Beistands. Biblisch intensiviert wird dieser Zugang vor allem in geistlichen Predigten, die in typologischer Konstruktion Österreich als unser Israel und Daun als zweiten Gideon bezeichnen - so etwa in Pater Abundius’ „Lob- und Dank-Rede ueber die den 18. Junii 1757 [...] höchst-ansehnliche Victori“. 117

Gerade aus diesem Blickwinkel ist die Konstruktion fiktiver, aber persönlich-emotionaler Verhältnisse (etwa in Form der Anrede an die Soldaten mit dem Passus „Deine Kaiserin“), jeweils nach gattungsspezifischer Aufgabenstellung (Predigt, Ode etc.) stärker mythologisch oder christlich unterlegt, zu beurteilen. Der Hauptakzent liegt in den meisten dieser Textgattungen nicht auf der Schilderung der Schlacht, sondern auf dem zu einem Gigantentreffen stilisierten Zweikampf zwischen Maria Theresia und Friedrich. Dieses Ringen der als Heroen angesehenen Herrscher provozierte geradezu die Anwendung zahlreicher topischer Muster, indem häufig das ganze Arsenal der Weltgeschichte aufgeboten wird, um Friedrich II. zu dekonstruieren und ihn von bedeutenden Helden der Antike wie Alexander, Cyrus und Caesar negativ abzusetzen, so etwa in der Schrift „Der von der Oesterreichischen Lerche überwundene Preußische Adler“.

\footnotetext{
113 Vgl. Füssel / Sikora, Schlachtengeschichte, 22; Jahn, Medialität, 91, 101-103.

${ }^{114}$ Füssel, Das Undarstellbare, 349.

115 Jahn, Medialität, 91.

${ }^{116}$ N. C., Ode auff den großen Sieg, eingelegt in: HHStA, Mainzer Erzkanzlerarchiv, Militaria, 68.

${ }^{117}$ Pater Abundius, Lob- und Dank-Rede, 11 bzw. 2 f.
} 
Im Gegensatz zur quantitativ dominierenden Textproduktion mit ihrem überbordenden Arsenal historischer und literarischer Vergleiche existiert kaum eine wirkliche „Bildwürdigkeit“ der Schlacht von Kolín. ${ }^{118}$ Die charakteristischen Hauptmomente dieser für die Österreicher siegreichen Begegnung werden somit vor allem in den Textgattungen deutlich. Bildliche Schlachtenszenen können aufgrund der in der Frühen Neuzeit beliebten Anwendung topischer Muster diesen Anspruch hingegen nur ungenügend erfüllen. Erst ein halbes Jahrhundert später kristallisierten sich - weniger auf österreichischer Seite (Daun) als vielmehr auf preußischer (Friedrich) - markante visuelle Personenprofile heraus, etwa auf der bekannten Darstellung, auf der Friedrich II. niedergeschlagen auf einer Kanone (oder einer Bank) sitzt (1801). ${ }^{119}$ Zum Teil werden auch (nichtrealisierte) bildkünstlerische und architektonische Gattungen (Denkmal, Tempel) zu Ehren des österreichischen Sieges bei Kolín literarisch imaginiert, etwa eine Säule in der Schrift „Eine wegen des über die Preussen erhaltenen glorreichen Siegs auffgerichtete Oestreichische Ehren-Säule“120, die eigentlich auf dem Schlachtfeld hätte platziert werden sollen. Eine Transformation „realer“ Denkmäler in andere Medien findet auch in der Druckgrafik statt, etwa bei Friedrich II., der seine Zustimmung zur Ausführung von Monumenten verweigerte, die in der Folge in Stichen in anderer Weise Realisierung fanden. ${ }^{121}$ Der Siebenjährige Krieg stellt aus mediengeschichtlicher Perspektive eine grundsätzliche Zäsur dar: In bisher ungekannter Fülle wurden populäre und kunsthandwerkliche Medien wie Vivatbänder und Tabakdosen produziert, und auf unterschiedliche Objekten übernahm man die in Form von Flugblättern und Kupferstichen kursierenden realistischen oder fiktiven Schlachtenbilder. ${ }^{122}$ In diesem Fall spielt die „Plurimedialität frühneuzeitlicher Medienereignisse“"123 von Andenkengattungen bis zur Musik eine tragende Rolle, wobei unterschiedliche Öffentlichkeiten als „Resonanzräume““124 für die entsprechenden Medien zur Verfügung standen. Bezeichnenderweise geben vor allem die überlieferten Medaillen nicht vornehmlich die Schlacht von Kolín selbst wieder, sondern die ruhmreichen Folgen dieses Sieges - mithilfe des motivischen Einsatzes von Trophäen und Triumphpforten sowie des Militär-Maria-Theresien-Ordens. Die Anzahl der unterschiedlichen Prägungen zu Kolín ist aber durchaus beachtlich. ${ }^{125}$ Im Vordergrund steht die den Gedenkmedaillen immanente „Speicher-

\footnotetext{
${ }^{118}$ Vgl. Schort, Politik, 476, mit dem Hinweis, dass die Bildpublizistik keine wesentliche Rolle in den publizistischen Auseinandersetzungen während des Siebenjährigen Krieges spielte.

119 London, The British Museum, Inv.-Nr. 1917, 1208.149.

${ }^{120}$ Eingelegt in: HHStA, Mainzer Erzkanzlerarchiv, Militaria, 68.

${ }^{121}$ Vgl. Schumacher, Der Siebenjährige Krieg, 258-260, Abb. 13.

${ }^{122}$ Füssel, Evidenz.

${ }^{123}$ Weißbrich / Carl, Präsenz, 96.

${ }^{124}$ Dainat, Der Siebenjährige Krieg, 16.

${ }^{125}$ Habsburg-Lothringen, Schau- und Denkmünzen, Nr. CXXIX-CXXXII.
} 
und Erinnerungsfunktion“126, die dazu führte, dass Bilder und Beischriften ein feinsinniges „Referenzsystem“127 kreierten, mittels dessen sie das aktuelle Ereignis mit bewährten Topoi verknüpften. Die Anwendung prominenter Bildmuster bot zudem den Vorteil, dass das aktuelle Geschehen als quasi zeitlos präsentiert respektive kontextualisiert werden konnte, womit in medienspezifischer Hinsicht ein deutlicher Gegenpol zur Reportagegrafik vorliegt, die grundsätzlich zu größerer Wirklichkeitsnähe verpflichtet ist.

Im Gegensatz zu anderen Ereignissen des 18. Jahrhunderts war der Ausgang einer Schlacht grundsätzlich außerordentlich umstritten: Der auf dem Schlachtfeld errungene Sieg musste (besonders in den in Bezug auf Sieg oder Niederlage umstrittenen Fällen) nachträglich „medial fixiert und transportiert werden“. ${ }^{128}$ Dies bedeutete in der Regel einen höheren medialen und argumentativen Aufwand, um die Deutungshoheit der jeweiligen Partei entsprechend abzusichern. Das zur Zeit des Geschehens selbst unüberschaubare und letztlich wechselhafte Ereignis einer Schlacht wurde somit erst ex post zu einem medialen Ereignis, und dabei spielten - wie skizziert - verschiedene Medien in unterschiedlichen Formaten bei der Durchdringung der Öffentlichkeiten eine Rolle - von Vivatbändern bis zum Te Deum. ${ }^{129}$ Gerade anhand einer Schlacht kann somit der spezifische Charakter eines Medienereignisses des 18. Jahrhunderts, der vornehmlich als selektive Konstruktion zu verstehen ist, besonders anschaulich gemacht werden. Ziel war es letztlich, das Ereignis selbst vom unkontrollierbaren, gegebenenfalls chaotischen und nichtsteuerbaren „ephemeren Präsenzmedium“ in ein dauerhaftes „Speichermedium“ mit abgesichert-kontrollierter Deutungshoheit zu überführen. ${ }^{130}$

Bei der Analyse der Fachliteratur fällt auf, dass in Bezug auf Schlachtenereignisse vergleichsweise wenig von den Akteuren der Medienproduktion die Rede ist. So wie von mehreren Handlungsträgern (Künstlern wie dahinter stehenden Auftraggebern) gesprochen werden kann, ist auch die unterschiedliche Rezeption eines Ereignisses im Kontext unterschiedlicher Öffentlichkeiten zentral, wie eine Publikation Sebastian Küsters bereits im Titel demonstriert: „Vier Monarchien - vier Öffentlichkeiten“ “131. Grundsätzlich sind in Bezug auf die Akteure zwei Handlungsmuster erkennbar: Während bei König Friedrich II. eine „planmäßige Einflußnahme auf die politische Publizistik“132 im Sinne eines „Federkrieg[es]“133 zu konstatieren ist, der dazu führte, dass der Preußenkönig gezielt bestimmte „Residenten“ in

\footnotetext{
${ }^{126}$ Weißbrich, Medaillen, 155.

${ }^{127}$ Weißbrich, Medaillen, 167.

${ }^{128}$ Weißbrich, Höchstädt, 156.

${ }^{129}$ Füssel, Das Undarstellbare, 323 f.; Jahn, Medialität, 98 f.

${ }^{130}$ Weißbrich / Carl, Präsenz, 82.

${ }^{131}$ Küster, Vier Monarchien, 22; vgl. zur Ausdifferenzierung der Öffentlichkeiten ebd., 136 f.

132 Welke, Pressepolitik, 174.

${ }^{133}$ Welke, Pressepolitik, 177; zur grafischen Produktion vgl. Komander, Wandel.
} 
die Zeitungsredaktionen entsendete, die vom Hof stets mit den neuesten Informationen versorgt wurden, ${ }^{134}$ ist auf der Gegenseite eine nur „langsame Reaktion des österreichischen Regierungsapparates“135 nachzuweisen. In Wien hatte man etwa erstaunlicherweise keine Übersicht über die im Reich erscheinenden Nachrichtenblätter. ${ }^{136}$ Demgegenüber scheinen Buchhandel und Verlage in Österreich an Bedeutung gewonnen zu haben, wobei die konkreten Verbindungslinien zwischen Beauftragung und Aktionsradien noch weitgehend im Dunkeln liegen: Maria Theresia hatte dafür gesorgt, dass Buchdruck, Verlagswesen und Unterricht in den Erbländern einen deutlichen Aufschwung nehmen konnten. ${ }^{137}$ Hier ist besonders Johann Thomas von Trattner (1717-1798) als Vertreter des Typs eines geschäftstüchtigen Aufsteigers zu nennen. In der von ihm verlegten „Ode auf den bey Chotzemitz durch die Allerhöchsten kaiserlich-königlichen Waffen über die Preußen [...] erfochtenen Sieg“ (1757) wird etwa bereits am Beginn ein prominenter Topos deutscher Publizistik thematisiert, nämlich der Preußenkönig als vermeintlicher Retter deutscher Libertät. Offenbar reagierte Trattner damit bewusst auf den deutschen Pressemarkt. Joseph Ritter von Kurzböck (1736-1792) steigerte das patriotische Gefühl seiner Landsleute (besonders seit 1757) durch die Produktion einer wahren Masse von Neuigkeits-, Jubel- und Huldigungsgedichten, für die er Philipp Hafner (1735-1764) und Michael Denis als Autoren gewinnen konnte. ${ }^{138}$ Besonders Hafner und Denis sind als „literarische Fixpunkte einer wahren Flut kriegerischer Gelegenheitsgedichte“ - vor allem in Flugblättern - ${ }^{139}$ anzusprechen. Dazu kommt die Monopolstellung des Unternehmers van Ghelen. ${ }^{140}$ Um 1760, also kurz nach der Schlacht von Kolín, ist somit generell die interessante Entwicklung nachweisbar, dass der „literarische Markt“ die Macht des Staates und die Autonomie der Dichter zu beeinflussen begann. ${ }^{141}$ Private Unternehmer hofften also zunehmend, mit ihren Produkten Geld verdienen zu können. ${ }^{142}$ Trotzdem bleibt angesichts der massiven Präsenz süddeutscher Stecher folgende von der Forschung bereits gestellte Frage virulent: „Warum versuchte der Hof nicht, sich selbst durch Werbetexte zu unterstützen?“143 Besonders deutlich wird dies angesichts der Reaktionslosigkeit Wiener Drucker auf manches Schlachtenereignis. ${ }^{144}$ Möglicherweise war aber dem Hof durch die Verleihung entsprechender

\footnotetext{
${ }^{134}$ Welke, Pressepolitik, $177 \mathrm{f}$.

135 Welke, Pressepolitik, 183.

${ }^{136}$ Welke, Pressepolitik, 186.

${ }^{137}$ Zeman, Kurzböck, 145.

138 Zeman, Kurzböck, 148 f., 152.

${ }^{139}$ Zeman, Kurzböck, 154.

${ }^{140}$ Küster, Vier Monarchien, 134.

${ }^{141}$ Birgfeld, Kriegspoesie, 224.

142 Küster, Vier Monarchien, 127.

${ }^{143}$ Küster, Vier Monarchien, 133.

${ }^{144}$ Vgl. Küster, Vier Monarchien, 135.
} 
Druckprivilegien an Kurzböck, Ghelen und Trattner ${ }^{145}$ bewusst, dass diese Verleger aufgrund von Abhängigkeitsmechanismen die Interessen Habsburgs vertreten würde.

Schließlich sind aber auch zeitbedingte und übergreifende Gemeinsamkeiten zwischen Österreich und Preußen zu konstatieren: In Malerei und Skulptur scheinen während des Siebenjährigen Krieges und unmittelbar danach keine großen Aufträge vergeben worden zu sein, deren Aufgabe es gewesen wäre, den Krieg im Dienst des österreichischen oder preußischen Staats glorifizierend wiederzugeben. Die Resonanz des Krieges in der zeitgenössischen Historienmalerei kann als äußerst gering bezeichnet werden, ${ }^{146}$ wobei in Preußen durch das Wirken Bernhard Rodes (1725-1797) der Radius noch wesentlich weiter war als in Österreich. ${ }^{147}$ Offensichtlich existierte ein Misstrauen des preußischen Königs gegenüber künstlerischer Selbstdarstellung in zeitgeschichtlichem Zusammenhang nach dem Siebenjährigen Krieg, was sich auch im Fehlen einer „histoire métallique“148 äußerte, der wohl prominentesten frühneuzeitlichen Form der Memoria an kriegerische Ereignisse.

\section{Maria Theresias Genesung von den Blattern im Jahr 1767}

Im 18. Jahrhundert traten die Blattern (Pocken) so stark wie noch nie in Europa auf. ${ }^{149}$ Sie grassierten in Städten und auf dem Land und trafen aufgrund der hohen Ansteckungsgefahr im Gegensatz zur Pest auch die Oberschicht. Die Krankheit beeinflusste in diesem „Zeitalter der Pocken“ mehrfach die Thronfolge in europäischen Herrscherhäusern und konnte sogar die Existenz ganzer Dynastien bedrohen. ${ }^{150}$ In den 1760er Jahren war die Dynastie HabsburgLothringen mehrfach von der Seuche betroffen: Innerhalb weniger Jahre verstarben Erzherzog Karl Joseph (1745-1761), Erzherzogin Johanna Gabriela (1750-1762) und Isabella von Parma (1741-1763), die erste Ehefrau Josephs II. Nur vier Jahre später erkrankte Kaiserin Maria Josepha (1739-1767), die zweite Ehefrau Josephs, und verstarb nach kurzer Krankheit. Bei der Pflege ihrer Schwiegertochter infizierte sich auch Maria Theresia: Am 27. Mai wurde ihre Erkrankung, am 6. Juni ihre Genesung offiziell verkündet. ${ }^{151}$

\footnotetext{
${ }^{145}$ HHStA, Oberstmarschallamt 603 (1776-1783), Fasz. V/776, o. Nr., o. Pag.; HHStA, Reichshofrat, Fabriks-, Gewerbe- und Handlungsprivilegien, 11, Fasz. 1, fol. 66-81.

${ }^{146}$ Meier, Buchillustration, 68; vgl. Schumacher, Der Siebenjährige Krieg.

147 Jacobs, Rodes, 134-137.

${ }^{148}$ Meier, Buchillustration, 69.

${ }^{149}$ Vgl. Weigl, Bevölkerungswachstum, 116.

${ }^{150}$ Pollmeier, Pocken, 139-141. Die Bourbonen waren vom Aussterben der Dynastie bedroht, als 1711/12 bis auf Ludwig XIV. „alle in der Rangfolge direkten nächsten Thronerben“ durch Pocken starben (ebd., 143). In Österreich änderte sich die Thronfolge durch Pockenerkrankungen nach dem Tod Ferdinands IV. (1633-1654) und Josephs I. (1678-1711).

${ }^{151}$ HHStA, Zeremonialprotokolle 32 (1767), fol. 86r, 123r-124r.
} 
In der Frühen Neuzeit wurden die Erkrankung und vor allem der Tod eines Regenten als Kontinuitätsbruch der Herrschaft sowie als Bedrohung der Stabilität des Landes empfunden. ${ }^{152}$ Um dies abzuwenden und die damit einhergehende Unsicherheit zu bewältigen, musste zum Ersten auf institutioneller Ebene die Erbfolge abgesichert sein. ${ }^{153}$ Zum Zweiten wurden wie auch bei anderen Gefahren (Seuchen, Kriege etc.) Bittgebete in den Kirchen des jeweiligen Herrschaftsgebietes angeordnet. War die Krise überstanden, wurde mit der Anordnung von Dankgebeten und der Abhaltung eines Te Deum reagiert. Religiöse Rituale im Sinne einer Informations- und Bewältigungsstrategie zu verfügen, war eine standardisierte Reaktion auf Krisensituationen und sollte die Bevölkerung auf einen möglicherweise negativen Ausgang des Geschehens vorbereiten. Es handelt sich dabei um eine Vorgehensweise, die nicht nur auf das Erzhaus Habsburg beschränkt war, sondern auch bei anderen Dynastien zu beobachten ist. ${ }^{154}$ Die von Joseph II. eingeforderten Handlungen bei der Erkrankung und anschließenden Genesung Maria Theresias wurden von einer breiten medialen Rezeption (Dankgottesdienste, Zeitungsberichte, gedruckte Gedichte und Predigten) begleitet, die in ihrer Dimension signifikant und in der Dynastie singulär ist.

Erkrankung und Genesung Maria Theresias riefen eine Fülle von Berichten in unterschiedlichen Medien hervor. Am Beginn stand eine in ungedruckten (Dekrete, Briefe, Zeremonialprotokolle etc.) und gedruckten Quellen (Zeitungsberichte, Circularien etc.) überlieferte Informationspolitik des Hofes. Darauf folgten ephemere Dankbezeugungen (Dankgottesdienste, Te Deum etc.) und gedruckte Würdigungen (Gedichte, Predigten, etc.), die in erster Linie auf Initiativen höfischer und hofnaher Stellen und Personen beruhten.

Um die baldige glückliche Genesung dieser Theüresten Lants Mutter zu erbitten, ordnete Joseph II. nach Ausbrechen der Blattern bei Maria Theresia an, dass die geistlichen und weltlichen Stände, besonders aber die geistlichen Korpora, Spitäler, Schulen, Universitäten, Beamten und Magistrate, an Bittgebeten teilnehmen sollten. Dadurch sollte Gott bewogen werden, den unglückl[ichen] Fall mit Barmherzigkeit abzuwenden und der Allergnädigsten Lants-Mutter eine Vollkommene Geneßung, und dauerhaffte Gesundheit Baldens zu schenken. ${ }^{155}$ Die Durchführung dieser Anordnung wurde der geistlichen Obrigkeit

\footnotetext{
152 Vgl. Kampmann, Tod des Herrschers, 264.

153 Kampmann, Tod des Herrschers, 265. Bei der Erkrankung Maria Theresias war dies durch die Mitregentschaft Josephs bereits gewährleistet. Seit dem Tod Franz I. Stephans (1708-1765) war Joseph Kaiser und Mitregent in den habsburgischen Erblanden; vgl. Reinöhl, Mitregentschaft.

${ }^{154}$ Bisher wurden Erkrankungen von Herrschern v. a. in Bezug auf Tod, politische Konsequenzen und die Memoria untersucht. Untersuchungen, die sich explizit mit der Genesung von Herrschern, dem damit einhergehenden Zeremoniell und der medialen Resonanz beschäftigen, stehen hingegen noch aus. ${ }^{155}$ HHStA, Hausarchiv, Ministerium des Inneren, Fasz. 7, Konv. 17, fol. 84, 27. Mai 1767.
} 
überlassen. ${ }^{156}$ In und vor Wien wurden in allen Kirchen und in der Kammerkapelle der Hofburg für sechs Tage zu festen Betstunden öffentliche Gebete abgehalten, ${ }^{157}$ und am 2. Juni begann ein vierzigstündiges Gebet. ${ }^{158}$ Wider Erwarten besserte sich der Zustand Maria Theresias, und am 6. Juni wurde wiederum mittels Dekreten ihre Genesung verkündet. ${ }^{159}$ Circularien sollten in ausreichender Anzahl schleunigst gedruckt und verbreitet werden, um die Abhaltung eines feierlichen Te Deum zu verfügen. Damit war das Bestreben verbunden, Gott den schuldigste[n] Dank öffentlich abzustatten. ${ }^{160}$ Durch die Abhaltung eines Te Deum, das im Reich bei bedeutenden Ereignissen stattfand, wurde die Tragweite der Genesung verdeutlicht. ${ }^{161}$ Da der Grund für diesen Lobgesang bereits vorab angekündigt wurde, diente er eher einer „Verankerung im Gedächtnis als der Erstinformation“ und verfügte über eine öffentlichkeitspolitische Dimension. ${ }^{162}$ Um die Nachricht vom drohenden Tod der Herrscherin und später von ihrer Genesung im Herrschaftsgebiet zu verbreiten, wurde auf kirchliche Infrastrukturen zurückgegriffen ${ }^{163}$ und während der Gottesdienste die positive Nachricht verlesen. ${ }^{164}$ Gottesdienste und Predigten im Land erreichten wohl nahezu die gesamte Bevölkerung und sind daher als effektive Medien der Kommunikation zu lesen. ${ }^{165}$ Einen wesentlich kleineren Rezipientenkreis sprach das „Wienerische Diarium“ an, das in jeder Ausgabe über den Gesundheitszustand der Erkrankten informierte ${ }^{166}$ und die in der Residenzstadt Wien stattfindenden Dankgottesdienste anlässlich der Genesung aufzählte und teilweise beschrieb. ${ }^{167}$ Mit den Berichten über den Verlauf der Erkrankung der Regentin schien es noch am ehesten die Intentionen einer vermeintlich objektiven Vermittlung des Geschehens zu verfolgen, doch unterlagen die prinzipielle Verkündung von Nachrichten sowie die Aufforderung, Dank zu bezeugen, bei dieser Zeitung der Kontrolle und Steuerung des Hofes.

\footnotetext{
${ }^{156}$ HHStA, Hausarchiv, Ministerium des Inneren, Fasz. 7, Konv. 17, fol. 84, 27. Mai 1767.

${ }^{157}$ HHStA, Zeremonialprotokolle 32 (1767), fol. 110v-111v, 29. Mai 1767.

158 Tagebuch des Fürsten Johann Josef Khevenhüller-Metsch, Bd. 6, 243. In anderen Städten ist ein ähnliches, aber kleiner dimensioniertes Vorgehen zu verzeichnen. So wurde in Graz beispielsweise mehrmals ein vierzigstündiges Gebet abgehalten, eine feierliche Prozession von der Stadtpfarrkirche zur Mariahilfkirche begangen und ein freiwilliger Fasttag initiiert, vgl. StLA, Laa. A. Antiquum II. K. 15, H. 93, 30. Mai 1767; Wienerisches Diarium, 13. Juni 1767.

${ }^{159}$ HHStA, Zeremonialprotokolle 32 (1767), fol. 123r-124r; KLA, RLh, 88-65, Durchreisen, Vermählungen, Todesfälle, fol. 31r-v, 6. Juni 1767.

${ }^{160}$ HHStA, Hausarchiv, Ministerium des Inneren, Fasz. 7, Konv. 17, o. Pag., 7. Juni 1767.

${ }^{161}$ Friedrich, Drehscheibe Regensburg, 497.

162 Friedrich, Drehscheibe Regensburg.

163 Küster, Vier Monarchien, 121.

${ }^{164}$ Vgl. für die Verbreitung der Information innerhalb kirchlicher Strukturen u. a. Vortrag, welcher Sonntags den 12. Julii 1767 [...] abgelesen werden solle.

165 Küster, Vier Monarchien, 121.

${ }^{166}$ Eine beinahe identische Berichterstattung erfolgte in der Preßburger Zeitung, 30. Mai bis 25. Juli 1767.

${ }^{167}$ Wienerisches Diarium, 27. Mai bis 22. Juli 1767. Das „Wienerische Diarium“ berichtet auch über Feierlichkeiten in anderen Städten, etwa in Graz, Preßburg (Wienerisches Diarium, 13. Juni 1767), Brünn (Wienerisches Diarium, 24. Juni 1767) und Enns (Wienerisches Diarium, 27. Juni 1767).
} 
Die größte Dichte von Dankbezeugungen in Form kirchlicher Feste gab es in Wien: Hier wurden zwischen dem 14. Juni und 22. Juli mindestens 30 Feiern in den verschiedenen Kirchen in und vor der Stadt abgehalten. Die von Institutionen und Gemeinschaften initiierten Feierlichkeiten gingen über die Anordnung Josephs und gottesfürchtige Dankbezeugungen hinaus, denn die Genesung erwies sich für die Veranstalter als ideale Möglichkeit, sich zu profilieren. Am 20. Juni vermerkt das „Wienerische Diarium“ gar, dass von den obersten Hofstäben, Kollegien, Gemeinden und Gesellschaften bei den Feierlichkeiten mit Besetzung der Musik, Ausschmückung und Beleuchtung der Kirchen gleichsam miteinander um den Vorzug gestritten werde. ${ }^{168}$ Der Umstand, dass nun auch die Verwendung von Pauken und Trompeten bei kirchlichen Prozessionen wieder erlaubt wurde, unterstreicht, dass die Dankbezeugungen auch von offizieller Seite gutgeheißen wurden. ${ }^{169}$ In Wien konzentrierten sich die Feierlichkeiten auf religiöse Feste; außerhalb der Residenzstadt sind hingegen auch einige wenige andere ephemere Dankbezeugungen überliefert: Am 15. August wurde in Preßburg ein Feuerwerk aufgeführt, ${ }^{170}$ und in Luxemburg wurde das Stadthaus festlich beleuchtet und mit symbolischen Bildern geschmückt. ${ }^{171}$ Bei der Geburt Josephs war die Errichtung von Illuminationen von Maria Theresia eigens angeordnet worden. Bei ihrer Genesung hingegen gehörten diese nicht zu den vorgesehenen Festivitäten, sondern nur die Durchführung religiöser Rituale. In beiden Fällen griffen Teile der Wiener Bevölkerung die unterschiedlichen vom Hof forcierten Festgattungen - Illuminationen oder Dankgottesdienste - auf und nutzten sie für öffentlichkeitswirksame Huldigungen. Höhepunkt und Abschluss der Dankgottesdienste stellte eine am 22. Juli unter Anwesenheit Maria Theresias in St. Stephan in Wien vollzogene Feier dar. Von der Hofburg aus zog Maria Theresia in einem Staatswagen und reicher Begleitung durch die Stadt und nahm in der Metropolitankirche am Te Deum und dem Hochamt teil, während das kleine und große Geschütz abgefeuert wurden. ${ }^{172}$ Der Wiener Erzbischof Christoph Anton Migazzi (1714-1803) betonte gleich zu Beginn seiner Predigt, dass ohne allen Widerspruch [...] heute der glückseligste, und feyerlichste aus allen den Tagen [sei], die wir bisher mit Lobopfern, und Danksagungen für die erwünschte Wiedergenesung Theresiens, unserer geliebten Monarchin, zugebracht haben. Bei anderen Festen würde das

\footnotetext{
168 Wienerisches Diarium, 20. Juni 1767; vgl. auch Tagebuch des Fürsten Johann Josef Khevenhüller-Metsch, Bd. 6, 247.

${ }^{169}$ Verbot von Pauken und Trompeten bei kirchlichen Prozessionen 1754: FHKA, 111 Patente (1754), 111.22. Zur Verwendung von Pauken und Trompeten nach der Genesung vgl. Wienerisches Diarium 24. Juni 1767; HHStA, Zeremonialprotokolle 32 (1767), fol. 138r, 17. Juni 1767.

${ }^{170}$ Wienerisches Diarium, 22. August 1767; Preßburger Zeitung, 19. August 1767; Wien, Österreichische Nationalbibliothek, Kartensammlung, KI 111228.

${ }^{171}$ Vgl. Thewes, Luxemburg, 56.

172 HHStA, Zeremonialprotokolle 32 (1767), fol. 150r.
} 
Volk für die Genesung danken, heute aber vereiniget sie sich selbst die beste Monarchin mit ihrem Volke, um dem Herrn [...] für seine Gnade zu danken. ${ }^{173}$ Seit dem Tod Franz Stephans (1765) war Maria Theresia nicht mehr öffentlich aufgetreten, und erst Joseph scheint sie überzeugt zu haben, am 22. Juli am Te Deum teilzunehmen. ${ }^{174}$ Während der Ausfahrt Maria Theresias läuteten alle Kirchenglocken in und vor der Stadt, ${ }^{175}$ und beim Zug zurück zur Hofburg wurden eigens geprägte silberne Medaillen ausgeworfen. ${ }^{176}$ In Wien wurde die Stadtbevölkerung durch die Dankgottesdienste in den Kirchen, den Zug Maria Theresias durch die Stadt, das Auswerfen der Münzen und Medaillen, das Abfeuern der Geschütze sowie das Läuten der Kirchenglocken visuell und akustisch als Präsenzöffentlichkeit des Ereignisses einbezogen.

Die Drucklegung der Predigten, Sendschreiben, Reden und Festbeschreibungen im „Wienerischen Diarium“ überführte die Feste und Rituale in ein dauerhaftes Medium und machte sie einer breiteren Öffentlichkeit zugänglich. Zwischen Juni und Juli 1767 erschienen rund 40 Druckschriften, welche die Genesung Maria Theresias literarisch würdigten und überformten: 10 Predigten (im Umfang von 20 bis 36 Seiten), etwa 20 kurze (im Umfang von 4 bis 6 Seiten) und 5 längere Gedichte sowie einige Reden und Sendschreiben. ${ }^{177}$ Die Druckschriften zählen im Sinne der Herrscherpanegyrik die Taten der Regierung Maria Theresias auf und beschreiben und loben ihre und Josephs Tugenden. Gleichzeitig bieten sie Begründungen für die Erkrankung und Genesung an und kontextualisieren so das Ereignis: Gott habe Maria Theresia erkranken lassen, um die Gläubigen zu prüfen ${ }^{178}$ oder sie für ihr Fehlverhalten zu bestrafen. ${ }^{179}$ Maria Theresia trage, so der Tenor, als Vorbild an Frömmigkeit und Gläubigkeit keine Schuld, denn immer wieder werden ihre Qualitäten als Stütze der Kirche betont. ${ }^{180}$ Dies ist im Kontext der Pietas Austriaca und des dynastisch verstandenen Gottesgnadentums zu deuten, denn das Erzhaus Habsburg habe, so eine Quelle, auf die Frömmigkeit all seine Hoheit gebauet, und die Gottseligkeit, als ein besonders Eigenthum seinen Erben zurückgelassen. ${ }^{181}$ Die Genesung Maria Theresias wurde der Gnade und Barmherzigkeit Gottes zugeschrieben, denn auch in der zweiten Hälfte des 18. Jahrhunderts

\footnotetext{
${ }^{173}$ Migazzi, Dankrede, fol. A2r-v.

174 Tagebuch des Fürsten Johann Josef Khevenhüller-Metsch, Bd. 6, 252; Wienerisches Diarium, 22. Juli 1767.

175 HHStA, Zeremonialprotokolle 32 (1767), fol. 169v-170r.

${ }^{176}$ HHStA, Zeremonialprotokolle 32 (1767), fol. 176r, 22. Juli 1767.

${ }^{177}$ Einige Drucke sind nur durch Verlagsankündigungen bekannt und im Original nicht überliefert; vgl. u. a. die Ankündigung des Verlegers Johann Thomas von Trattner im Wienerischen Diarium, 24. Juni 1767.

${ }^{178}$ Klemm, Ode, fol. 2v.

${ }^{179}$ Holzmayer, Rede, $4 \mathrm{f}$.

${ }^{180}$ Migazzi, Dankrede, fol. B3r; Puff, Lob- und Dankrede, 6; P. Norbertus a Sancto Anselmo, Dankrede, 3.

${ }^{181}$ Holzmayer, Rede, 8. Vgl. zur Frömmigkeit des Hauses Habsburg Coreth, Pietas Austriaca.
} 
erschienen „Frömmigkeit, Gebete und sittliches Wohlverhalten“182 noch als bestes Heilmittel. Die Predigten, die zu allen festlichen Anlässen einer Stadt oder eines Landes gehalten wurden und die Vorkommnisse besprachen und deuteten, boten zugleich theologische Auslegungen an. ${ }^{183}$ Gerade in Krisenzeiten waren sie ein wichtiges Medium, um das (politisches) Geschehen zu interpretieren. ${ }^{184}$ Sie erreichten eine breite Öffentlichkeit; gedruckt wurden sie allerdings in geringer Auflage und waren nur für einen kleinen Empfängerkreis sozial hochstehender Persönlichkeiten gedacht. ${ }^{185}$ Auch in den Gedichten werden religiöse Bezüge hergestellt, wohingegen die beinahe gänzlich fehlenden mythologischen Verweise die Inszenierung der Genesung als Zeichen des Gottesgnadentums unterstreichen. Dies steht in der Tradition der habsburgischen Argumentationsstrategie, Schicksalsschläge als direkte Eingriffe der göttlichen Vorsehung zu deuten und dadurch eine Regentschaft als gottgefällig zu bekräftigen. ${ }^{186}$ Ein wiederkehrendes Motiv ist dabei die Gegenüberstellung der Krankheit Maria Theresias mit jener des alttestamentarischen Königs Hiskia (Ezechias). ${ }^{187}$ Der Prophet Jesaja übermittelte dem erkrankten König die göttliche Botschaft, dass er sterben müsse. Als Hiskia daraufhin zu Gott betete, erhörte dieser seine Bitten und verlängerte sein Leben um fünfzehn Jahre (2 Kg 20, 1-11; Jes 38, 1-22). Der berühmte Jesuit Ignaz Wurz (1731-1784) begann seine Predigt vor der königlichen Hofkammer am 23. Juni in St. Peter in Wien mit einem direkten Vergleich zwischen Maria Theresia und dem König des Alten Testaments: Ezechias und Maria Theresia, an Frömmigkeit und allen königlichen Tugenden gleich groß, beyde ein Geschenk des Himmels, die Hoffnung und das Glück ihrer Völker, beyde werden in der Mitte ihrer Tage von einer tödlichen Krankheit eben so unvermuthet als gefährlich angefallen. ${ }^{188}$ Die Verwendung dieser Erzählung impliziert die Annahme, dass Gott durch Bittgebete milde gestimmt werden könne und Krankheiten und Todesankündigungen aufheben würde. Im Jahr 1767 seien es aber nicht Gebete Maria Theresias, sondern die Gebete, das Flehen, die Seufzer und die Tränen der Untertanen und Josephs gewesen, die Gott veranlasst hätten, Maria Theresia genesen zu lassen. In einem Sendschreiben an das Theresianische Kollegium stellte der Arzt des Wiener Waisenhauses St. Marx, Maximilian Locher, fest, dass das allgemeine Gebet, desgleichen in unsrer Residenzstadt annoch nicht erlebet worden, [...] unsrer allergnädigsten Frauen das

\footnotetext{
${ }^{182}$ Vocelka, Glanz, 323. Die behandelnden Ärzte werden aber z. B. von Wurz erwähnt: Wurz, Dankrede, 20. Nach dem Jahr 1767 setzte sich Maria Theresia für die sogenannte Blatterninokulation ein. Sie ließ ihre Kinder und Enkelkinder sowie 65 mittellose Kinder impfen; vgl. Pollmeier, Pocken, 146.

${ }^{183}$ Herzog, Geistliche Wohlredenheit, 18.

${ }^{184}$ Gestrich, Absolutismus, 151.

185 Küster, Vier Monarchien, 125.

${ }^{186}$ Matsche, Caesar et Imperium, $95 \mathrm{f}$.

${ }_{187}$ Wurz, Dankrede, 3 f.; Chemnitz, Dankgebet, 27; Primisser, Empfindungen, fol. 2r; Vers sur la maladie, 8.

188 Wurz, Dankrede, $3 \mathrm{f}$.
} 
Leben erhalten, und die Gesundheit wieder hergestellet ${ }^{189}$ habe. Durch die Teilnahme an den Bitt- und Dankgottesdiensten wurde die Bevölkerung in das Geschehen einbezogen und ihr in Predigten und Druckschriften vermittelt, dass ein christlicher Lebenswandel sowie Gebete die Genesung bewirkt hätten. ${ }^{190}$ Eine große Teilnahme des Volkes an Gebeten für den Herrscher wurde im 18. Jahrhundert als hohes Ansehen des Fürsten gedeutet und öffentlich propagiert. ${ }^{191}$ Dass die scheinbar bereits totgeglaubte Herrscherin doch überlebte, wird in den Gedichten mit dem emphatisch wiederkehrenden - und auch in anderen Zusammenhängen nachweisbaren Motiv Sie lebt ${ }^{192}$ oder Therese lebt ${ }^{193}$ beschrieben. Ein Dichter, der sich selbst in der Tradition preußischer Siegeslieder sieht, schließt sein Triumphlied über die kriegerischen Erfolge Maria Theresias und die Opferbereitschaft ihrer Soldaten mit den folgenden Worten: Nun singen wir statt Schlachtgesang, / Es lebt Theresia! / In Paucken und Trompettenklang; / Es lebt Theresia. ${ }^{194}$ Die dominierenden Narrative - die Bedeutung des Glaubens, die Gebete und Gott als Beschützer Maria Theresias - wurden visuell und textlich auf einer eigens geprägten Medaille aufgegriffen. Der Revers zeigt die Personifikation der Religion mit einem Räucherfass vor einem Altar kniend, und die Umschrift nennt Gott als den Erhalter der Kaiserin. ${ }^{195}$ Die Genesung Maria Theresias hatte vor allem in Wien große Resonanz in verschiedenen Medien; visualisiert wurde sie aber nur auf geprägten Medaillen. Es wurden weder Druckgrafiken zum Verkauf angeboten noch Gemälde oder Skulpturen hergestellt. ${ }^{196}$ Dies dürfte zum einen mit der prinzipiellen Undarstellbarkeit einer Genesung zusammenhängen und zum anderen mit der Tatsache, dass Ereignisse der Regierungszeit Maria Theresias generell in sehr geringem Ausmaß verbildlicht wurden. Anders verhält es sich in Frankreich: Nachdem Ludwig XV. (1710-1744) während des Österreichischen Erbfolgekrieges 1744 in Metz erkrankt war, wurde seine Genesung mit vergleichbarer Intensität wie jene Maria Theresias in Wien gefeiert. Jedoch dienten neben gedruckten Oden auch ephemere Medien wie Triumphbögen und

\footnotetext{
${ }^{189}$ Locher, Sendschreiben, fol. 3r. Ähnlich auch: Rede auf die Genesung; Lob- und Dankgebet für die glückliche Wiedergenesung; Wurz, Dankrede, 19; P. Norbertus a Sancto Anselmo, Dankrede, 7.

190 Gestrich, Absolutismus, 128, 153.

191 Brüggemann, Herrschaft und Tod, 147.

${ }^{192}$ U. a. Klemm, Ode, fol. 4r; Sonnenfels, Bey der Danksagungsfeyer, fol. 2r; Denis, Ode, fol. 2r; Burkard, Der Triumph Theresiens, fol. 2r.

193 Rohleder, Freudenbezeigung.

${ }^{194}$ Lied eines kaiserl. königl. Grenadiers, 10.

${ }^{195}$ Kunsthistorisches Museum Wien, Münzkabinett, Inv.-Nr. 1770bß; Habsburg-Lothringen, Schau- und Denkmünzen, Nr. CXCVII (Medaille von Anton Widemann); Stich der Medaille in der Bibliothèque nationale de France, Inv.-Nr. D 206654. Eine zweite Medaille anlässlich der Genesung ist abgedruckt in HabsburgLothringen, Schau- und Denkmünzen, Nr. CXCVIII.

${ }^{196}$ Erst im 19. Jahrhundert wurde die Genesung verbildlicht, indem etwa „Maria Theresia nach ihrer Genesung vom Volke jubelnd begrüßt“ ins Bild gesetzt wird; vgl. Danzer, Kaiserin Maria Theresia, vor 1.
} 
Illuminationen ${ }^{197}$ sowie Bildwerke zur Inszenierung dieses Medienereignisses: CharlesAntoine Coypel (1694-1752) fertigte ein Gemälde an, das die Personifikation Frankreichs darstellt und sich zur Erinnerung an Ludwigs Genesung im Appartement der Königin in Versailles befand. ${ }^{198}$ Zudem wurden Druckgrafiken produziert und eine Stichserie zu den Feierlichkeiten während des Einzugs und Aufenthalts in Straßburg nach der Genesung des Königs veröffentlicht. ${ }^{199}$

Das eigentliche Geschehen der Erkrankung und Genesung war bei Maria Theresia - wie auch bei der Geburt und Taufe Josephs - nichtöffentlich. Aufgrund der Ansteckungsgefahr wurden wahrscheinlich nur wenige Personen zu Maria Theresia vorgelassen. Dazu gehörten ihre Ärzte Gerard van Swieten (1700-1772) und Anton Freiherr von Störck (1731-1803), sowie Hofpersonal zur Bedienung und Kaiser Joseph II., der bereits 1757 an den Pocken erkrankt war $^{200}$ und sich deshalb nicht anstecken konnte. Ein eigentlich nichtöffentliches und in höfischer Abgeschlossenheit stattfindendes Geschehen, wie es die Genesung darstellt, musste habsburgischen Traditionen folgend über standardisierte und erprobte Nachrichtenkanäle veröffentlicht, vermittelt und verbreitet werden. Kommunikation und Verbreitung sowohl der negativen Nachricht der Erkrankung als auch der positiven Wendung der Genesung im gesamten Herrschaftsgebiet lagen im Interesse des Hofes, um notwendige Handlungen wie Bittgebete und Danksagungen der Untertanen zu befördern. Durch höfische Informationsstrategien wie Dekrete, Briefe, Circularien und die Anordnung von Gebeten und des Te Deum entwickelte sich die Nachricht von der Genesung zu einem Kommunikationsereignis. Vor allem höfische und hofnahe Stellen griffen dieses in einer Fülle religiöser Rituale auf, an denen die Bevölkerung im Herrschaftsgebiet durch die Teilnahme an den Dankgottesdiensten aktiv partizipieren konnte. Die Wiener Stadtbevölkerung in ihrer Gesamtheit wurde darüber hinaus durch den Zug Maria Theresias durch die Stadt, das Auswerfen der Medaillen, das Läuten der Kirchenglocken und das Abfeuern der Geschütze zur eigentlichen Präsenzöffentlichkeit. Darauf reagierten Medienproduzenten, indem sie die außergewöhnliche und positive Nachricht und die religiösen Rituale aufgriffen, in einem Prozess der Abstraktion und verdichteten Kommunikation das historische Ereignis der Genesung vor allem in Textmedien überformten, die Präsenzöffentlichkeit auf die wesentlich größere Medienöffentlichkeit ausweiteten und so das Medienereignis der Genesung erzeugten.

\footnotetext{
${ }^{197}$ Hours, Louis XV., 57-59. Zu deren politischer Bedeutung und zu den Machtkämpfen am französischen Hof während der Erkrankung vgl. Hours, Louis XV., 37-70.

198 Gouzi, Coypel.

199 Claude Nicolas Malapeau (nach Alexandre Roslin), Convalescence de Louis XV à son retour de Metz (nach 1744); Weis, Représentation des fêtes.

${ }^{200}$ HHStA, Ältere Zeremonialakten, Fasz. 48, Konv. 4.
} 
Es waren Einzelpersonen und Gruppen, welche die mediale Präsenz und Dimension dieses Ereignisses vervielfältigten: Die Veranstalter der Dankgottesdienste (Hofstäbe, Kollegien etc.) wollten nicht nur ihren Dank gegenüber Gott bezeugen, sondern sich durch die Pracht der Feierlichkeiten selbst präsentieren. Auch die von Klerus und Dichtern verfassten Druckschriften verfolgten im Sinne der Herrscherpanegyrik die Intention, Maria Theresia und Joseph zu huldigen, verfolgten aber auch wirtschaftliche Zwecke. Bei den Dichtern waren es neben einigen anonym gebliebenen Verfassern bekannte Autoren wie Michael Denis ${ }^{201}$, Joseph von Sonnenfels (1732/33-1817) ${ }^{202}$ oder Pietro Metastasio (1698-1782) ${ }^{203}$, die wiederholt Huldigungsschriften und Gedichte für Mitglieder des Erzhauses verfassten. Der Klerus hingegen verfolgte wohl keine wirtschaftlichen Interessen, sondern wollte mit dem Verkauf der Predigten bei kirchlichen und weltlichen Würdenträgern positiv auffallen ${ }^{204}$ und die Möglichkeit zur Verbreitung theologischer Ansichten nutzen.

Bei der Geburt Josephs (1741) befand sich der Hofbuchdrucker van Ghelen bei der Erzeugung von Huldigungsschriften noch in einer Monopolstellung; im Zuge der Berichterstattung zur Schlacht von Kolín (1757) war bereits der Verleger Johann Thomas von Trattner wichtiger. Bei der Genesung Maria Theresias (1767) behielt van Ghelen zwar in Bezug auf die Nachrichtenvermittlung mittels des „Wienerischen Diariums“ seine wichtige Stellung bei, bei allen anderen Publikationsgattungen hatte aber Trattner das Monopol übernommen. In seinem Verlag erschienen mindestens fünf Predigten, fünfzehn Gedichte und zwei Gebete, hauptsächlich auf Deutsch, einige auch auf Französisch, Italienisch und Latein. Van Ghelen veröffentlichte nur zwei Predigten und vier Gedichte, Joseph Ritter von Kurzböck und Maria Theresia Schulz jeweils eine Schrift. ${ }^{205}$ Diese markante Veränderung bei den Druckaufträgen spiegelt den Aufstieg von Trattners Unternehmen zu einem „beispiellosen Druckimperium“ wider, der durch die Förderung des Hofes begünstigt wurde. ${ }^{206}$ Die große Anzahl von Druckschriften, die Trattner veröffentlichte, war sicher wirtschaftlichen Ambitionen geschuldet und ist zugleich ein Indiz für die große Nachfrage nach kurzen Druckschriften. Da Trattner das Interesse des Hofes bediente, die Regentschaft Maria Theresias und Josephs positiv darzustellen und den beiden Personen zu huldigen, können die von ihm gedruckten Schriften gleichzeitig als Mittel gesehen werden, um sich die Gunst seiner Förderer zu erhalten.

\footnotetext{
201 Wimmer, Denis.

${ }^{202}$ Karstens, Lehrer; ders., Sonnenfels.

203 Pietro Metastasio erhielt zum Dank von Maria Theresia eine mit Brillanten und dem Porträt Maria Theresias geschmückte goldene Tabatiere; vgl. Wienerisches Diarium, 22. August 1767.

${ }^{204}$ Predigten wurden fallweise direkt an Erzbischof oder Hof geschickt; vgl. Küster, Vier Monarchien, 125.

${ }^{205}$ Außerhalb Wiens wurden einige Schriften auch in Linz (Johann Michael Pramsteidel), Klagenfurt (Joseph Johann Schotter) oder Günzburg (Wageggische Schriften) herausgegeben.

${ }^{206}$ Bachleiter / Eybl / Fischer, Geschichte des Buchhandels, 136 f.
} 


\section{Fazit}

Geburten, Schlachten und Genesungen waren ohne Zweifel zentrale Momente für ein Herrscherhaus und wurden auch entsprechend gefeiert und kommuniziert. Die vielfältigen Medialisierungen der drei hier kurz vorgestellten Geschehen zeugen zum einen von der Existenz einer „staatliche[n] Öffentlichkeitsarbeit“, die der Verbreitung positiver und herrschaftsfestigender Nachrichten sowie der Selbstdarstellung diente und für die - im Sinne der Praxis ständiger Herrschaftssicherung - der entsprechende Tugendkanon zelebriert und demonstriert wurde. ${ }^{207}$ Zum anderen stellte die staatlich initiierte Informationspolitik und Nachrichtenvermittlung nur einen geringen Anteil an der gesamten Medienproduktion dar. Den viel größeren Teil schufen dem Hof in unterschiedlicher Weise nahestehende Personen und Gruppen durch die Produktion von Schriften oder die Errichtung von Illuminationen. Die Aufforderung, bestimmte Feste zu veranstalten, kam zwar vom Hof, inhaltliche Ausgestaltung und Intensität der Durchführung oblagen jedoch der Bevölkerung und Einzelakteuren. In den Jahren 1741, 1757 und 1767 beförderten Verleger, Dichter, Künstler, Prediger sowie adelige und bürgerliche Auftraggeber somit eine Intensivierung von Medienereignissen in Abhängigkeit von der höfischen Praxis der Nachrichtenverbreitung. Sie erfüllten ihre strukturelle Funktion bei der Herrscherhuldigung zum einen aus wirtschaftlichen Interessen. Darüber hinaus diente ihr Engagement aber auch vielfach dem Ansehen ihrer Institutionen. Ein instruktives Beispiel ist hier das Freudengerüst der Stadt Wien anlässlich der Geburt Josephs: Hier verherrlichte die Stadt zwar Maria Theresia und den ersehnten Thronfolger, repräsentierte aber vor der Bevölkerung auch sich selbst. Diese hier besonders augenscheinliche multipolar verschränkte Kommunikationsstrategie ist ein charakteristisches Merkmal der Herrscherpanegyrik der Frühen Neuzeit und vermag auch die ungewöhnliche Intensität von Huldigungen in Form von Privatinitiativen zu erklären.

Bei näherer Betrachtung zeigen sich aber auch unterschiedliche mediale Dimensionen aufgrund divergierender ereignisspezifischer Strukturen: Geburt und Krankheit sind letztlich - wiewohl von hoher dynastischer Relevanz - Geschehen mit nichtöffentlichem Charakter. Trotzdem waren sie, wie hier gezeigt werden konnte, in den unterschiedlichen Öffentlichkeiten in intensiver Weise medial gegenwärtig. Hier war eine effektive Steuerung durch wenige Akteure möglich und sinnvoll, da nur einige wenige Personengruppen einen echten Einblick in die konkreten Abläufe des Geschehens hatten. Geburten waren zudem als körperliche Prozesse der weiblichen Sexualität besonders schambehaftet, sodass eine Reportage über den eigentlichen Akt gänzlich undenkbar war. Ganz anders verhält es sich bei einer Schlacht, die als öffentliches

${ }^{207}$ Küster, Vier Monarchien, 120. 
Ereignis in ihren Medialisierungen praktisch kaum zu steuern war. Allerdings unterlag auch hier die Interpretation unterschiedlichen Akteuren, die in diesem Fall aus gutem Grund möglichst rasch versuchten, die Deutungshoheit über das Ereignis zu erlangen. Gerade bei kriegerischen Auseinandersetzungen ist deshalb die mit Abstand größte mediale Breite in der Rezeption eines Geschehens zu konstatieren. Entsprechend klafft der jeweilige Grad an „Präsenzöffentlichkeit“ bzw. „Medienöffentlichkeit“208 bei den drei hier skizzierten Ereignistypen weit auseinander. Bei den dynastischen Ereignissen von Geburt und Genesung existierte keine Präsenzöffentlichkeit während des eigentlichen Geschehens. Eine Präsenzöffentlichkeit bestand stattdessen bei performativen Ritualen wie Gottesdiensten sowie Inszenierungen wie etwa Illuminationen, welche die Nachrichten in ihrer Bedeutsamkeit und Tragweite für die Anwesenden erst richtig fassbar und erlebbar machten. Das Medienereignis konstruierte sich dabei gleichermaßen aus dem Nachrichtenereignis, seiner Deutung durch die Medienproduzenten und der Anteilnahme der Bevölkerung. Zugleich ist auffällig, dass bei allen thematisierten Beispielen die Textmedien deutlich dominieren. Druckgrafiken und vor allem Gemälde spielen nur eine vergleichsweise bescheidene Rolle.

Im Kontext der Traditionen einer spezifisch habsburgischen „Medienpolitik“ lassen sich auch ritualisierte Reaktionen auf die drei Ereignisse erkennen. Das betrifft insbesondere die wiederkehrenden und lebensphasenbedingten familiär-dynastischen Ereignisse wie Geburten, Hochzeiten und Sterbefälle, bei deren medialer Vermittlung die dynastische Kontinuität die schlechthin zentrale Kernbotschaft darstellt. Hier ist auch die Genesung von den Blattern im Sinne eines glücklich abgewendeten Sterbefalls zu nennen. Gerade das Beispiel der Geburt Josephs kurz nach dem Herrschaftswechsel des Jahres 1740 zeigt, dass die unter Kaiser Karl VI. etablierten Strukturen der Herrscherhuldigung mit identischen Akteuren und Produzenten unter Maria Theresia fortbestanden und sich die höfische Festkultur letztlich eng an habsburgischen Traditionen orientierte. Während somit strukturell durchaus eine Kontinuität in der habsburgischen Repräsentationspraxis deutlich wird, sind aus inhaltlicher Perspektive Neuorientierungen zu erkennen, da die bewährten Topoi habsburgischer Herrscherhuldigung bei einer weiblichen Herrscherin ${ }^{209}$ nicht bruchlos anzuwenden waren. Auch hier besitzt das Ereignis der Schlacht eine mediale Sonderstellung, da deren Visualisierung im Betrachtungszeitraum - formal und inhaltlich - weniger habsburgische Sonderwege als

\footnotetext{
${ }^{208}$ Vgl. Rudolph, Das Reich als Ereignis, 422-426.

${ }^{209}$ Vgl. Telesko, Herrschaftssicherung.
} 
vielmehr ausgeprägte europäische Trends spiegelt, wie etwa bei der Grafikproduktion die starke Position der süddeutschen Verlegerzentren Augsburg und Nürnberg. ${ }^{210}$

Zusammenfassend kann festgehalten werden, dass alle drei hier behandelten Ereignisse der Ära Maria Theresias - wie bereits am Beginn des Jahrhunderts - vor allem mythologischen und/oder biblischen Deutungsmustern unterlagen. Es ging hier somit durchwegs weniger um ein ausgeprägtes Interesse am realen Handlungskern der Geschehnisse als vielmehr um die vielfältigen Möglichkeiten ihrer Instrumentalisierbarkeit, die nicht zu einer Vertiefung der unterschiedlichen Facetten des jeweiligen Ereignisses selbst, sondern zu einer „Standardisierung“ und „Institutionalisierung der Medialisierung“ führte, um hier von Harriet Rudolph eingeführte Begriffe aufzugreifen. ${ }^{211}$ Schlachtendarstellungen stellen wohl das einprägsamste Beispiel für diese Art überregionaler Standardisierung des Bildrepertoires dar. Die angesprochene Instrumentalisierung der Ereignisse konnte unterschiedlichen Zwecken dienen, wobei im Fall der Genesung Maria Theresias von den Blattern die Stärkung der emotionalen Bindung des Volkes an ihre kranke Herrscherin zu nennen ist. Unterstützt wurde dieser Prozess durch die Verordnung von Volksfesten und Gottesdiensten, also von Veranstaltungen, die wiederum als performative Garantie von Herrschaftssicherung medial verbreitet und propagiert werden konnten. Der besondere Fall einer weiblichen Thronerbin, die zu Beginn ihrer Herrschaft von feindlichen Mächten bedrängt wurde und gleichzeitig den „rettenden“ Thronfolger zur Welt brachte, bot Huldigungsautoren zudem ein einmaliges und zutiefst „schicksalhaftes“ Narrativ für die emotionale Identifikation der Untertanen mit ihrer Herrscherin. Der damit unweigerlich verbundene Aspekt der „Gefühlspolitik“212 im Sinne der Stärkung der affektiven Bindung zwischen Herrscher und Volk dürfte ein Element sein, das die unterschiedlichen Medialisierungen der Ereignisse in der Ära Maria Theresias verbindet und das darüber hinaus die Herrschaftsrepräsentation im Zeitalter des aufgeklärten Absolutismus in neue Bahnen lenken sollte. ${ }^{213}$

\footnotetext{
${ }^{210}$ Vgl. Schort, Politik, 476, mit dem Hinweis, dass die Betreiber der druckgrafischen Produktionsstätten in den Reichsstädten Augsburg und Nürnberg bemüht war, bei keiner der kriegführenden Parteien Anstoß zu erregen, was wiederum die Praxis der Zensur bedingte.

${ }^{211}$ Rudolph, Das Reich als Ereignis, 423, 425.

${ }^{212}$ Grundlegend: Frevert, Gefühlspolitik.

${ }^{213}$ Das in Anmerkung 1 genannte Projekt zu Maria Theresia steht auch im Zeichen der Forschungen zu diesem weiten Themenbereich.
} 


\section{Summary}

\section{Between Panegyric and Factual Report.}

\section{Structure and Purpose of "Media Events" at the Time of Maria Theresa}

This paper examines three decisive historical events that took place during the reign of Maria Theresa of Austria. It considers them as "media events" comprising the birth of Joseph, the heir to the throne (1741), the Battle of Kolín (1757) and Maria Theresa's recovery from smallpox (1767). In general, media events during the early modern period point to the construction of messages not merely confined to imparting information. The intrinsic aim of this paper is to analyse the political and historical dimension and both the structure and dynamics of the three media events in terms of their visual and textual genres. Furthermore, the paper refers to performative practices and examines the public information strategies of the players involved. The birth of Archduke Joseph, the first son of Maria Theresa, is remarkable given the public's wide involvement in the celebrations. They did so through their use of aphorisms and ephemeral festive architectures. The birth itself served as an event intended to promote a feeling of community and shared unity. Its ulterior purpose was to exert a stabilising influence in the difficult early stages of Maria Theresa's rule. The Battle of Kolín marked the first victory over the Prussian King in the Seven Years' War and became the subject of a significantly personalised form of commemorative journalism in which the role of the heroic redemptress or redeemer was on occasion ascribed to Maria Theresa or to Field Marshal Daun. This indicates that while wars were especially prone to a superficially simple exercise in communications, their coverage in the media had an enormous impact on the overall population. On the other hand, Maria Theresa's convalescence from smallpox was characterised by the population's religious anxieties regarding the fate of their sovereign. Church sermons served as a pivotal means of imparting information, of interpreting the event and of describing how it had transpired. Moreover, these three types of events display a deep divide concerning their respective degrees of "Präsenzöffentlichkeit" - meaning the public as recipients of Habsburg propaganda - and "Medienöffentlichkeit" - which refers to those imparting such propaganda (cf. Harriet Rudolph). In the case of dynastic events such as births or recoveries from serious illness, there was no "Präsenzöffentlichkeit" to witness what had happened. Consequently, performative rituals such as church services and contemporary mises en scene were the sole means of ensuring that such news was understandable and accessible among the public. Hence, while structural continuities became evident in the exercise of Habsburg representation under the rule of Maria Theresa, they were also accompanied by substantial realignments: in general, 
the conventional and universally accepted topoi of paying homage to male rulers proved inadequate in regard to the case of transfer to a female sovereign.

\section{Ungedruckte Quellen}

Graz, Steiermärkisches Landesarchiv (StLA)

- $\quad$ Laa. A. Antiquum II. K. 14, H. 89; K. 15, H. 93.

Klagenfurt, Kärntner Landesarchiv (KLA)

- Repräsentation und Kammer, Landeshauptmannschaft (RLh), 88-65, Durchreisen, Vermählungen, Todesfälle.

- Ständisches Archiv, C Akten, Abteilung 1, Schachtel 398.

Wien, Österreichisches Staatsarchiv, Allgemeines Verwaltungsarchiv (AVA)

- Kriegsarchiv, ZSt HKR SR KzlA XIII, 158.

Wien, Österreichisches Staatsarchiv, Finanz- und Hofkammerarchiv (FHKA)

- Sammlungen und Selekte, Kontrakte und Reverse, C-649.

- 111 Patente (1754), 111.22.

Wien, Österreichisches Staatsarchiv, Haus-, Hof- und Staatsarchiv (HHStA)

- Ältere Zeremonialakten, Fasz. 48, Konv. 4.

- Hausarchiv, Familienakten, 110, Fasz. 23.

- Hausarchiv, Ministerium des Inneren, Fasz. 3, Konv. 13; Fasz. 7, Konv. 17.

- Kriegsakten 358 [1757-1763], Fasz. alt 416.

- Mainzer Erzkanzlerarchiv, Militaria, 68.

- Oberstmarschallamt 603 (1776-1783), Fasz. V/776.

- Reichshofrat, Fabriks-, Gewerbe- und Handlungsprivilegien, 11, Fasz. 1.

- Sonderbestände, Flugschriften, 5 (1755-1810).

- Zeremonialprotokolle 18 (1741/1742); 26 (1757/1758); 32 (1767).

\section{Gedruckte Quellen}

Allgemeines Frolocken und Zuruffen des Volcks, Ihro Majestät Unserer Allerdurchleuchtigsten Frauen, Frauen Mariae Theresiae [etc.] Wegen höchst=beglückten Fürgang und Seegnung nach erfreulichster Entbindung Josephi, Wien: Heyinger 1741.

Archenholz, Johann Wilhelm von, Geschichte des Siebenjährigen Krieges in Deutschland von 1756 bis 1763, Karlsruhe: Schmieder 1791.

Aus der Zeit Maria Theresias. Tagebuch des Fürsten Johann Josef Khevenhüller-Metsch, kaiserlichen Oberhofmeisters 1742-1776, Bd. 6: 1764-1767, hrsg. v. Rudolf Khevenhüller-Metsch / Hans Schlitter, Leipzig / Wien 1917.

Beschreibung deren in der königl. Burg zu Wien den 13. Martii 1741. prächtig vollbrachten Tauf-Ceremonien des neu-gebornen [...] Erz-Herzogen zu Osterreich Joseph Benedicti, Wien: van Ghelen 1741.

Beschreibung Der Sinn-Bildern Und In-Schriften, Welche zu höchsten Ehren Der Beglücktesten Geburt Des Durchleuchtigsten Erz-Herzogs Leopold, Prinzen von Asturien \&c. \&c. bey der am 14. 15. und 16. Aprill. 1716. angestelt-freudenvollen Beleuchtigung Allhiesig-Kaiserlicher Haupt- und Residenz-Stadt Wien, gesehen worden, Wien: Schönwetter 1716.

Beschreibung des Haupt- und Freuden-Schießens, Welches Von Ihro zu Hungarn und Böheim königl. Majestät Maria Theresia, Wegen erfreulicher Geburt Josephi, Dero erstgebornen Erz-Herzogens zu Oesterreich Der Wienerischen Burgerschaft gegeben worden, Wien: van Ghelen 1743. 
Burkard, Joseph, Der Triumph Theresiens, als Ihre kaiserl. königl. apostol. Majestät nach beglückter Genesung das erstemal öffentlich erschien, Wien: Trattner 1767.

Chareß, Ludwig Gottlieb Christian, Der Tag den Österreich vor höchst-glückseelig hält dieweil der Vorsicht-Arm den Stamm von Habsburg neuret und welchen Statt und Land mit gröster Andacht feyret [...], Nürnberg: o. V. 1741.

Chemnitz, Johannes Hieronymus, Dankgebet, welches wegen der erfreulichen Wiedergenesung der Kaiserinn Königinn Majestät [...] gebetete [...], Wien: Trattner 1767.

Cvnalis Honos Votivus Avito Avstriadvm Filio Josepho, Benedicto, Avgvsto, Hvngariae et Bohemiae [...], o. O. [1741].

Denis, Michael, Ode auf die Genesung Marien Theresiens, Wien: Trattner 1767.

- Poetische Bilder der meisten kriegerischen Vorgänge in Europa, seit dem Jahr 1756, Wien: Kurzböck 1760.

Der von der Oesterreichischen Lerche überwundene Preußische Adler [...], Graz: Widmannstätterische Erben [1757].

Habsburg-Lothringen, Maria Anna von [zugeschrieben], Schau- und Denkmünzen welche unter der Regierung der Kaiserinn Königinn Maria Theresia geprägt worden sind, Wien: Krauß 1782 (Nachdruck: Günther von Probszt, Schau- und Denkmünzen Maria Theresias, Graz 1970).

Hackmann, Friedrich August von, Die Höchst-glückliche Geburt Des Von Gott längst erbethenen Und Den 13. Merz 1741 [...] zum Trost endlich geschenckten Durchlauchtigsten Erz-Herzogen Josephs, Benedict, August, Wien: Heyinger 1741.

Holzmayer, Wolfgang, Rede auf die höchstbeglückte Genesung Ihro Kais. Königl. Apostol. Majestät Maria Theresia [...], Linz: Pramsteidel [1767].

Jubel-Ode auf den am 18ten Junii 1757 [...] ohnweit Planian erfochtenen herrlichen Sieges [...], Frankfurt a. M.: Kayserliche Hof-Buchhandlung 1745.

Klemm, Christian Gottlob, Ode auf die Genesung Ihro kaiserl. königl. Majestät Marien Theresiens, Wien: Trattner 1767.

Kurze Trostschrift für das klagende Oesterreich [...], Wien: o. V. 1760.

Lied eines kaiserl. königl. Grenadiers [...], Wien: Trattner 1767.

Lob- und Dankgebet für die glückliche Wiedergenesung Ihro Kaiserl. Königl. Apost. Majestät [...], Wien: Trattner 1767.

Locher, Maximilian, Sendschreiben an das königliche Adeliche Theresianische Kollegium über so erwünschte, als glückliche Genesung Ihrer Kaiserl. Königl. Apostol. Majestät Marien-Theresiens unserer Allergnädigsten Frauen, Wien: Trattner 1767.

Migazzi, Christoph Anton, Dankrede auf die glückliche Genesung Marien Theresiens [...], Wien: Erzbischöfliche Druckerei 1767.

N. C., Ode auff den grossen Sieg, welchen Seine Kayserliche Königliche Majestaet Maria Theresia den 18ten und 20ten Junii dieses 1757ten Jahrs bey Planian und Prag über die Preußische Armée erfochten, o. O. u. J.

Ode auf den bey Chotzemitz durch die Allerhöchsten kaiserlich-königlichen Waffen über die Preußen [...] erfochtenen Sieg, Wien / Prag: Trattner 1757.

Pater Abundius OFMCap, Lob- und Dank-Rede ueber die den 18. Junii 1757 [...] höchstansehnliche Victori [...], Steyr: Menhardt 1757.

P. L. C. V. H., Das über den unvermutheten Tod des Allerdurchlauchtigsten Großmächtigsten und unüberwindlichsten Fürsten und Herren Herren Carls des Sechsten erwehlten Römischen Kaysers [...] und Frau Frau Maria Theresia [...] allhier und in allen Erb=Landen geleistete Erb=Huldigung [...], o. O. 1740.

- Die durch die neu= aufgegangene Sonne Triumphierende Tugend und Liebe wurde, als die Allerdurchlauchtigste und Großmächtigste Fürstin und Frau, Frau, Maria Theresia [etc.] mit einem so lange gewünschten Erb= und Cron=Prinzen [... ] zum Heil und allgemeiner 
Freude dero allergetreuesten Unterthanen beglückseeligte und erfreute, Wien: van Ghelen 1741.

P. Norbertus a Sancto Anselmo, Dankrede auf die beglückte Genesung Ihro kaiserl. königl. apostolischen Majestät Marien Theresiens [...], Wien: van Ghelen 1767.

Peikhardt, Franz, Ehren-Rede dem grossen Geist Caroli VI. [...] In all=tieffester Trauer gehaltenen Leich-Besingnuß In der hohen Metropolitan-Kirchen zu St. Stephan [...], Wien: Heyinger 1741.

- Wunsch und Hoffnung der Königl. Residentz-Stadt Wienn, zur Erhaltung des göttlichen Seegens über den Neu-gebohrnen Durchleuchtigsten Erz-Herzogen Joseph, unter dem Schutz des Heiligen [...], Göttlichen Nähr-Vatters Josephi, Wien: Heyinger 1741.

Preßburger Zeitung, 30. Mai 1767 bis 25. Juli 1767 und 19. August 1767.

Primisser, Johann B., Empfindungen des Unterthans bey höchstbeglückter Genesung Marien Theresiens, von einem Tyroler, Wien: Trattner 1767.

Puff, Fridolin, Lob- und Dankrede bey Gelegenheit des feyerlichen Dankfestes [...] für die allertheuerste Genesung Ihro Majestät Maria Theresia [...], Günzburg: Wageggische Schriften 1767.

Rede auf die Genesung Ihrer Kaiserl. Königl. Apostol. Majestät Marien Theresiens [...], Wien: Trattner [1767].

Reiffenstuel, Ignatio, Wiennerischer Stadt-Danck Dem Drey-einigen GOtt umb wegen Der dem 13. April erfolgten Erfreulichsten Geburt Leopoldi [...], Wien: Schwendimann 1716.

Richter, Christoph, Erfreulichst-aufgehender Morgen-Stern, In Glücklichster Entbindung Mariae Theresiae Der Allerdurchleuchtigsten Königin, Und Höchst-erwünschten Geburt deß Königlichen Erb-Printzens [...] Josephi Da Auf Veranstaltung deren Hochlöblichen Land-Ständen deß Ertz-Hertzogthums Cärnthens in dessen Haupt-Stadt Clagenfurt den 20.ten Mertzen 1741, Klagenfurt: Kleinmayr 1741.

Richter, Christoph Gottlieb, Die Historie des Kriegs zwischen den Preußen und ihren Bundgenossen und den Österreichern“ [...], 6 Bde., Nürnberg: o. V. 1753-1763.

Rohleder, Friderich, Freudenbezeigung über die erwünschte Genesung unserer Allerdurchlauchtigsten Monarchin, Klagenfurt: Schotter 1767.

Schauplatz des gegenwärtigen Kriegs [...], Bd. 1, Nürnberg: Raspe 1756.

Sonnenfels, Joseph von, Bey der Danksagungsfeyer über die Genesung unserer geliebten Monarchinn, Wien: Trattner 1767.

Steißlinger, Johann Andreas [Stecher und Verleger], Das frohlockende Wien, Uber den, den 13. Martij 1741. von Ihro Königlichen Majestät zu Hungarn und Böheim, auch ErtzHertzogin zu Oesterreich höchsterfreulich zur Welt gebrachten Königlichen Printzen, Augsburg 1741.

Vers sur la maladie, et sur l'heureuse convalescence de sa Majeste l'Imperatrice Reine apostolique, Wien: Trattner 1767.

Vortrag, welcher Sonntags den 12. Julii 1767 wegen Ihro [...] Majest. glücklich erfolgter Wiedergenesung [...], nach geendigter Predigt und verlesenen Kirchen=Gebete, von denen Canzeln in der Stadt und auf dem Land des Nürnbergischen Gebiets abgelesen werden solle, Nürnberg: o. V. 1767.

Weis, Jean-Martin, Représentation des fêtes données par la ville de Strasbourg pour la convalescence du Roi; à l'arrivée et pendant le séjour de Sa Majesté en cette ville, Paris: Laurent Aubert 1745.

Wiennerische Beleuchtungen, oder Beschreibung aller deren Triumph- und Ehren-Gerüsten, Sinn-Bildern [...] Welche bey denen zu Ehren der höchst-gewünschten Geburt Josephi den 13. Martii [...], Wien: van Ghelen 1741 (Nachdruck: Wien 1978).

Wienerisches Diarium, 24. September 1729, 8. u. 15. März 1741, 27. Mai bis 22. Juli 1767, 22. August 1767, 10. November 1781, 21. Januar 1782. 
Wurz, Ignaz, Dankrede auf die beglückte Genesung Ihrer Kaiserl. Königl. Apostol. Majestät Marien Theresiens [...], Wien: Trattner 1767.

\section{Literatur}

Anklam, Ewa, Wissen nach Augenmaß. Militärische Beobachtung und Berichterstattung im Siebenjährigen Krieg (Herrschaft und soziale Systeme in der Frühen Neuzeit, 10), Münster 2007.

Arndt, Johannes, Herrschaftskontrolle durch Öffentlichkeit. Die publizistische Darstellung politischer Konflikte im Heiligen Römischen Reich 1648-1750 (Veröffentlichungen des Instituts für Europäische Geschichte Mainz. Abteilung für Universalgeschichte, 224), Göttingen 2013.

Bachleiter, Norbert / Franz M. Eybl / Ernst Fischer, Geschichte des Buchhandels in Österreich, Wiesbaden 2000.

Bauer, Volker, Höfische Gesellschaft und höfische Öffentlichkeit im Alten Reich. Überlegungen zur Mediengeschichte des Fürstenhofs im 17. und 18. Jahrhundert, in: Jahrbuch für Kommunikationsgeschichte 5 (2003), 29-68.

- Nachrichtenmedien und höfische Gesellschaft. Zum Verhältnis von Mediensystem und höfischer Öffentlichkeit im Alten Reich, in: Das Mediensystem im Alten Reich der Frühen Neuzeit (1600-1750), hrsg. v. Johannes Arndt / Esther-Beate Körber (Veröffentlichungen des Instituts für Europäische Geschichte Mainz. Abteilung für Universalgeschichte, Beiheft 75), Göttingen 2010, 173-194.

Birgfeld, Johannes, Kriegspoesie für Zeitungsleser oder Der Siebenjährige Krieg aus österreichischer Sicht. Michael Denis’ „Poetische Bilder der meisten kriegerischen Vorgänge in Europa seit dem Jahre 1756“ im Kontext des zeitgenössischen literarischen Kriegsdiskurses, in: „Krieg ist mein Lied“. Der Siebenjährige Krieg in den zeitgenössischen Medien, hrsg. v. Wolfgang Adam / Holger Dainat in Verbindung mit Ute Pott (Schriften des Gleimhauses Halberstadt, 5), Göttingen 2007, 215-239.

Böning, Holger, Der „gemeine Mann“ als Zeitungs- und Medienkonsument im Barockzeitalter, in: Das Mediensystem im Alten Reich der Frühen Neuzeit (1600-1750), hrsg. v. Johannes Arndt / Esther-Beate Körber (Veröffentlichungen des Instituts für Europäische Geschichte Mainz. Abteilung für Universalgeschichte, Beiheft 75), Göttingen 2010, 227-238.

Bösch, Frank, Europäische Medienereignisse, in: Europäische Geschichte Online (EGO), hrsg. v. Institut für Europäische Geschichte (IEG), Mainz 2010-12-03, URL: http://www.iegego.eu/boeschf-2010-de [Zugriff: 19.04.2016].

- / Patrick Schmidt (Hrsg.), Medialisierte Ereignisse. Performanz, Inszenierung und Medien seit dem 18. Jahrhundert, Frankfurt a. M. / New York 2010.

Broucek, Peter, Der Geburtstag der Monarchie. Die Schlacht bei Kolin 1757, Wien 1982.

Brüggemann, Linda, Herrschaft und Tod in der Frühen Neuzeit. Das Sterbe- und Begräbniszeremoniell preußischer Herrscher vom Großen Kurfürsten bis zu Friedrich Wilhelm II. (1688-1797) (Geschichtswissenschaften, 33), München 2015.

Coreth, Anna, Pietas Austriaca. Ursprung und Entwicklung barocker Frömmigkeit in Österreich, Wien 1959.

Dainat, Holger, Der Siebenjährige Krieg in den Medien, in: „Krieg ist mein Lied“. Der Siebenjährige Krieg in den zeitgenössischen Medien, hrsg. v. Wolfgang Adam / ders. in Verbindung mit Ute Pott (Schriften des Gleimhauses Halberstadt, 5), Göttingen 2007, 9-26.

Danzer, Alphons, Kaiserin Maria Theresia, die Stammmutter des Hauses Habsburg-Lothringen in ihrem Leben und Wirken, Wien 1888. 
Dietrich, Margret, Theater am Hofe - Zwischen Tradition und Wandel, in: Maria Theresia und ihre Zeit, hrsg. v. Walter Koschatzky, Salzburg 1979, 393-403.

Drentwett, Christine, Vom Nachrichtenmedium zum Nachrichtenthema. Medienberichterstattung, Wiesbaden 2009.

Emich, Birgit, Bilder einer Hochzeit. Die Zerstörung Magdeburgs 1631 zwischen Konstruktion, (Inter-)Medialität und Performanz, in: Kriegs/Bilder in Mittelalter und Früher Neuzeit, hrsg. v. ders. / Gabriela Signori (Zeitschrift für Historische Forschung, Beiheft 42), Berlin 2009, 197-235.

Fiala, Eduard, Katalog der Münzen- und Medaillen-Stempel-Sammlung des k. k. Hauptmünzamtes in Wien, Bd. 2, Wien 1902.

Frevert, Ute, Gefühlspolitik. Friedrich II. als Herr über die Herzen?, Göttingen 2012.

Friedrich, Susanne, Drehscheibe Regensburg. Das Informations- und Kommunikationssystem des Immerwährenden Reichstags um 1700 (Colloquia Augustana, 23), Berlin 2007.

Füssel, Marian, Auf der Suche nach der Erinnerung. Zur Intermedialität des Schlachtengedenkens an den Siebenjährigen Krieg im 18. und 19. Jahrhundert, in: Militärische Erinnerungskulturen vom 14. bis zum 19. Jahrhundert, hrsg. v. Horst Carl / Ute Planert (Herrschaft und soziale Systeme in der Frühen Neuzeit, 15), Göttingen 2012, 185-207.

- Das Undarstellbare darstellen. Das Bild der Schlacht im 18. Jahrhundert am Beispiel der Schlacht von Zorndorf (1759), in: Kriegs/Bilder in Mittelalter und Früher Neuzeit, hrsg. v. Birgit Emich / Gabriela Signori (Zeitschrift für Historische Forschung, Beiheft 42), Berlin 2009, 317-349.

- I Michael Sikora, Einführung. Schlachtengeschichte als Kulturgeschichte, in: Kulturgeschichte der Schlacht, hrsg. v. dens. (Krieg in der Geschichte, 78), Paderborn 2014, 11-26.

- Undarstellbare Evidenz. Zur Medialität der Schlachtenrepräsentation im 18. Jahrhundert, URL: http://www.recherche-online.net/marian-fuessel.html [Zugriff: 17.02.2016].

Garstka, Christoph, Das Herrscherlob in Russland. Katharina II., Lenin und Stalin im russischen Gedicht. Ein Beitrag zur Ästhetik und Rhetorik politischer Lyrik, Memmingen 2005.

Geelhaar, Margot, Maria Theresia und der Österreichische Erbfolgekrieg im Spiegel neulateinischer Huldigungsliteratur, Diss. phil. Wien 2010.

Gestrich, Andreas, Absolutismus und Öffentlichkeit. Politische Kommunikation in Deutschland zu Beginn des 18. Jahrhunderts (Kritische Studien zur Geschichtswissenschaft, 103), Göttingen 1994.

- Kriegsberichterstattung und Propaganda. Das Beispiel des „Wienerischen Diarium“ im Siebenjährigen Krieg 1756-1763, in: Augenzeugen. Kriegsberichterstattung vom 18. zum 21. Jahrhundert, hrsg. v. Ute Daniel, Göttingen 2006, 23-39.

Gouzi, Christine, Les tableaux commandés à Charles-Antoine Coypel (1694-1752) après la maladie de Louis XV à Metz en 1744: les personnifications du royaume de France, URL: https://vwm.hypotheses.org/354 [Zugriff: 06.06.2016].

Hengerer, Mark, Ludwig XIV. Das Leben des Sonnenkönigs (C. H. Beck Wissen, 2842), München 2015.

Herzog, Urs, Geistliche Wohlredenheit. Die katholische Barockpredigt, München 1991.

Hours, Bernard, Louis XV. Un portrait, Toulouse 2009.

Jacobs, Renate, Das graphische Werk Bernhard Rodes (1725-1797) (Kunstgeschichte, 35), Münster 1990.

Jahn, Bernhard, Die Medialität des Krieges. Zum Problem der Darstellbarkeit von Schlachten am Beispiel der Schlacht von Lobositz (1.10.1756) im Siebenjährigen Krieg, in: „Krieg ist mein Lied“. Der Siebenjährige Krieg in den zeitgenössischen Medien, hrsg. v. 
Wolfgang Adam / Holger Dainat in Verbindung mit Ute Pott (Schriften des Gleimhauses Halberstadt, 5), Göttingen 2007, 88-110.

Kampmann, Christoph, Der Tod des Herrschers als Grenze und Übergang. Die normative Funktion der Herrschermemoria in der Frühen Neuzeit, in: Grenzen und Grenzüberschreitungen. Bilanz und Perspektiven der Frühneuzeitforschung, hrsg. v. Christine Roll / Frank Pohle / Matthias Myrczek (Frühneuzeit-Impulse, 1), Köln / Weimar / Wien 2010, 263-270.

Karstens, Simon, Joseph von Sonnenfels (1733-1817), in: Multiple kulturelle Referenzen in der Habsburgermonarchie des 18. Jahrhunderts, hrsg. v. Wolfgang Schmale (Jahrbuch der Österreichischen Gesellschaft zur Erforschung des 18. Jahrhunderts, 24), Bochum 2010, 295-304.

- Lehrer - Schriftsteller - Staatsreformer. Die Karriere des Joseph von Sonnenfels (1733-1817) (Veröffentlichungen der Kommission für Neuere Geschichte Österreichs, 18), Wien 2011.

Körber, Esther-Beate, Schreiber und Leser politischer Flugschriften des frühen 17. Jahrhunderts, in: Das Mediensystem im Alten Reich der Frühen Neuzeit (1600-1750), hrsg. v. Johannes Arndt / ders. (Veröffentlichungen des Instituts für Europäische Geschichte Mainz. Abteilung für Universalgeschichte, Beiheft 75), Göttingen 2010, 195-205.

Komander, Gerhild H. M., Der Wandel des „Sehepuncktes“. Die Geschichte BrandenburgPreußens in der Graphik von 1648-1810 (Kunstgeschichte, 44), Münster / Hamburg 1995.

Küster, Sebastian, Vier Monarchien - vier Öffentlichkeiten. Kommunikation um die Schlacht bei Dettingen (Herrschaft und soziale Systeme in der Frühen Neuzeit, 6), Münster 2004.

Kunisch, Johannes, Laudons Nachruhm. Die Geschichte einer Sinnstiftung (NordrheinWestfälische Akademie der Wissenschaften. Vorträge. Geisteswissenschaften, 359), Opladen / Wiesbaden 1999.

Matsche, Franz, Caesar et Imperium. Die Fassadendekoration und das Deckenbild im Festsaal der ehemaligen Reichskanzlei in der Wiener Hofburg (Österreichische Akademie der Wissenschaften. Veröffentlichungen der Kommission für Kunstgeschichte, 10), Wien 2011.

Mauser, Wolfram, Maria Theresia: „Mutter der Völker“. Legendenbildung als Legitimation von Macht, in: Konzepte aufgeklärter Lebensführung. Literarische Kultur im frühmodernen Deutschland, hrsg. v. dems., Würzburg 2000, 137-148.

Meier, Hans J., Die Buchillustration des 18. Jahrhunderts in Deutschland und die Auflösung des überlieferten Historienbildes (Kunstwissenschaftliche Studien, 60), München 1994.

Nünning, Ansgar, Wie aus einem historischen Geschehen ein Medienereignis wird: Kategorien für ein erzähltheoretisches Beschreibungsmodell, in: Der Krimkrieg als erster europäischer Medienkrieg, hrsg. v. Georg Maag / Wolfram Pyta / Martin Windisch (Kultur und Technik, 14), Berlin 2010, 188-208.

Old, Hughes O., The Reading and Preaching of the Scriptures in the Worship of the Christian Church, Bd. 5, Grand Rapids / Cambridge 2004.

Opgenoorth, Ernst, Publicum - privatum - arcanum. Ein Versuch zur Begrifflichkeit frühneuzeitlicher Kommunikationsgeschichte, in: Kommunikation und Medien in Preußen vom 16. bis zum 19. Jahrhundert, hrsg. v. Bernd Sösemann (Beiträge zur Kommunikationsgeschichte, 12), Stuttgart 2002, 22-44.

Polleroß, Friedrich, Architektur und Panegyrik. Eine Allegorie der Jesuiten zur Geburt von Erzherzog Leopold Joseph (1682), in: Barock in Mitteleuropa. Werke, Phänomene, Analysen, hrsg. v. Martin Engel [u. a.] (Wiener Jahrbuch für Kunstgeschichte, 54), Wien / Köln / Weimar 2007, 375-391. 
Pollmeier, Heiko, Wie bei Bauern so bei Fürsten - Europäische Herrscherhäuser im „Zeitalter der Pocken“, in: „Gotts verhengnis und seine straffe“. Zur Geschichte der Seuchen in der Frühen Neuzeit (Ausstellungskataloge der Herzog August Bibliothek, 84), Wolfenbüttel 2005, 139-149.

Prange, Peter, Die Errichtung eines Freudengerüsts aus Anlaß der Geburt Josephs II., in: Barockberichte 31 (2001), 168-175.

Reinöhl, Fritz, Die Übertragung der Mitregentschaft durch Maria Theresia an Großherzog Franz Stephan und Kaiser Joseph II., in: Mitteilungen des Instituts für Österreichische Geschichtsforschung, Supplement 11 (1929), 650-661.

Rudolph, Harriet, Das Reich als Ereignis. Formen und Funktionen der Herrschaftsinszenierung bei Kaisereinzügen (1558-1618) (Norm und Struktur, 38), Köln / Weimar / Wien 2011.

- Lepanto - Die Ordnung der Schlacht und die Ordnung der Erinnerung, in: Militärische Erinnerungskulturen vom 14. bis zum 19. Jahrhundert, hrsg. v. Horst Carl / Ute Planert (Herrschaft und soziale Systeme in der Frühen Neuzeit, 15), Göttingen 2012, 101-127.

Schneider, Herbert, La Monarchia Lattina Trionfante von Antonio Draghi, Festa Musicale zur Geburt des Erbprinzen Joseph (1678) oder Wie legitim ist Lob und Kritik in der höfischen Panegyrik?, in: Der Fürst und sein Volk. Herrscherlob und Herrscherkritik in den habsburgischen Ländern der frühen Neuzeit, hrsg. v. Pierre Béhar (Annales Universitatis Saraviensis. Philosophische Fakultät, 23), St. Ingbert 2004, 109-144.

Schort, Manfred, Politik und Propaganda. Der Siebenjährige Krieg in den zeitgenössischen Flugschriften (Europäische Hochschulschriften. Reihe 3, 1023), Frankfurt a. M. [u. a.] 2006.

Schumacher, Doris, Der Siebenjährige Krieg in der bildenden Kunst. Von den Anfängen durch Johann Wilhelm Gleim und Friedrich II. bis zu den populären Illustrationsfolgen des späten 18. Jahrhunderts, in: „Krieg ist mein Lied“. Der Siebenjährige Krieg in den zeitgenössischen Medien, hrsg. v. Wolfgang Adam / Holger Dainat in Verbindung mit Ute Pott (Schriften des Gleimhauses Halberstadt, 5), Göttingen 2007, 240-267.

Schumann, Jutta, Die andere Sonne. Kaiserbild und Medienstrategie im Zeitalter Leopolds I. (Colloquia Augustana, 17), Berlin 2003.

Seitschek, Stefan, „Einige caeremonialpuncten bet(reffend)“. Kommunizierende Gefäße. Zeremonialprotokoll und Wiener Diarium als Quelle für den Wiener Hof (18. Jahrhundert), ungedr. Diplomarbeit Wien 2011.

Sösemann, Bernd, Zeremoniell und Inszenierung. Öffentlichkeit und dynastisch-höfische Selbstdarstellung in der preußischen Krönung und den Jubiläumsfeiern (1701-1851), in: Kommunikation und Medien in Preußen vom 16. zum 19. Jahrhundert, hrsg. v. dems. (Beiträge zur Kommunikationsgeschichte, 12), Stuttgart 2002, 85-135.

Stöckelle, Angela, Geburten und Taufen am barocken Kaiserhof, in: Österreich in Geschichte und Literatur 18 (1974), H. 3, 129-141.

Telesko, Werner, Herrschaftssicherung mittels visueller Repräsentation. Zur Porträtkultur Maria Theresias, in: Höfische Porträtkultur. Die Bildnissammlung der österreichischen Erzherzogin Maria Anna (1738-1789), hrsg. v. Eva Kernbauer / Aneta Zahradnik (Edition Angewandte), Berlin / Boston 2016, 37-47.

Thewes, Guy, Als Luxemburg österreichisch war. Zur Beziehung Österreichs und Luxemburgs im Zeitalter Maria Theresias, in: Das Zeitalter Maria Theresias. Meisterwerke des Barock. Eine Ausstellung der Österreichischen Galerie Belvedere Wien im Musée National d'Histoire et d'Art Luxemburg, hrsg. v. Michael Krapf, Luxemburg 2006, 4559.

Tschopp, Silvia S., Rhetorik des Bildes. Die kommunikative Funktion sprachlicher und graphischer Visualisierung in der Publizistik zur Zerstörung Magdeburgs im Jahre 1631, in: Kommunikation und Medien in der Frühen Neuzeit, hrsg. v. Johannes Burkhardt / 
Christine Werkstetter (Historische Zeitschrift. Beihefte [Neue Folge], 41), München 2005, 79-103.

Vocelka, Karl, Glanz und Untergang der höfischen Welt. Repräsentation, Reform und Reaktion im Habsburgischen Vielvölkerstaat (Österreichische Geschichte, 9), Wien 2004.

Vogel, Christine, „Evenemens mémorables“. Mediale (Selbst-)Inszenierungen des Parlement de Paris in der Auseinandersetzung mit Ludwig XV., in: Medienereignisse im 18. und 19. Jahrhundert. Beiträge einer interdisziplinären Tagung aus Anlass des 65. Geburtstags von Rolf Reichardt, hrsg. v. Christine Vogel / Herbert Schneider / Horst Carl (Ancien Régime, Aufklärung und Revolution, 38), München 2009, 19-32.

- Ort und Funktion der Bildpublizistik im plurimedialen Netz der Nachrichten- und Debattenkultur des 18. Jahrhunderts. Ein Beispiel, in: Interkulturelle Kommunikation in der europäischen Druckgraphik im 18. und 19. Jahrhundert, hrsg. v. Philippe Kaenel / Rolf Reichardt, Hildesheim 2007, 357-370.

Weigl, Andreas, Frühneuzeitliches Bevölkerungswachstum, in: Wien. Die Geschichte einer Stadt, Bd. 2: Die frühneuzeitliche Residenz, hrsg. v. Karl Vocelka, Wien 2003, 109132.

Weißbrich, Thomas, Die Schlacht bei Höchstädt/Blenheim 1704 als Medienereignis. Kriegsberichterstattung und Gelegenheitsdichtung im Spanischen Erbfolgekrieg, in: Kulturgeschichte der Schlacht, hrsg. v. Marian Füssel / Michael Sikora (Krieg in der Geschichte, 78), Paderborn 2014, 155-181.

- Medaillen und Gedächtniskunst. Aspekte militärischer Erinnerungskultur um 1700, in: Militärische Erinnerungskulturen vom 14. bis zum 19. Jahrhundert, hrsg. v. Horst Carl / Ute Planert (Herrschaft und soziale Systeme in der Frühen Neuzeit, 15), Göttingen 2012, 155-184.

- I Horst Carl, Präsenz und Information. Frühneuzeitliche Konzeptionen von Medienereignissen, in: Europäische Wahrnehmungen 1650-1850. Interkulturelle Kommunikation und Medienereignisse, hrsg. v. Joachim Eibach / Horst Carl (Historische Formationen Europas, 3), Hannover 2008, 75-98.

Welke, Martin, „[...] zu Österreichs Gloria durch Publicität mitzuwürcken“. Zur Pressepolitik des Kaiserhofes im Reich im 18. Jahrhundert, in: Mediengeschichte. Forschung und Praxis. Festgabe für Marianne Lunzer-Lindhausen zum 65. Geburtstag, hrsg. v. Wolfgang Duchkowitsch, Wien / Köln / Graz 1985, 173-193.

Wenzlik, Detlef, Kolin. Friedrichs erste Niederlage, Hamburg 1995.

Wilke, Jürgen, Die Zeitung, in: Von Almanach bis Zeitung. Ein Handbuch der Medien in Deutschland 1700-1800, hrsg. v. Ernst Fischer / Wilhelm Haefs / York-Gothart Mix, München 1999, 388-402.

Wimmer, Ruprecht, Der Jesuit Michael Denis, in: Maria Theresias Kulturwelt. Geschichte, Religiosität, Literatur, Oper, Ballettkultur, Architektur, Malerei, Kunsttischlerei, Porzellan und Zuckerbäckerei im Zeitalter Maria Theresias, hrsg. v. Pierre Béhar (Documenta Austriaca, 2), Hildesheim 2011, 45-58.

Zeman, Herbert, Der Drucker-Verleger Joseph Ritter von Kurzböck und seine Bedeutung für die österreichische Literatur des 18. Jahrhunderts, in: Die österreichische Literatur. Ihr Profil an der Wende vom 18. zum 19. Jahrhundert (1740-1830), Teil 1, hrsg. v. dems., Graz 1979, 143-178. 